\title{
Numerical Study and Second Law Analysis of Propeller-Type Vortex Generator in A Circular Pipe Flow
}

\author{
Omar Al-Abbasi \\ Mechanical Engineering Department \\ University of Bahrain
}

\begin{abstract}
In this study, the heat transfer and the thermo-hydraulic performance of pipe flow with propeller-type vortex generator inserts at the pipe inlet are numerically examined. The geometric effect of the blade angle associated with different air mass flow rates on the thermal performances was determined. In the present work, four-blade angles, $15^{\circ}, 30^{\circ} 45^{\circ}$, and $60^{\circ}$ were considered over a range of Reynolds number that was varied from 5000 to 30,000. A mathematical model was developed to simulate the flow. Thermal characteristics of the model and the governing equations were discretized and solved using finite element method in three-dimensional steady flow. The results were compared with existing experimental data. A good agreement was observed between the model and the experiment. Larger average heat transfer coefficient was achieved for a smaller blade angle, and on average, a reduction of $15^{\circ}$ in the blade angle resulted in a $4 \%$ increase in the outlet temperature as well as an $8 \%$ increase in the Nusselt number. The augmented vortex generator caused a sudden rise in the local heat transfer coefficient after the insert, and later a cyclic behavior for this coefficient is experienced. Considering both thermal and pressure drop points of view, the optimum blade angle was determined to be $60^{\circ}$, using the performance evaluation criteria.
\end{abstract}

Keywords:- Heat transfer enhancement; Propeller-type vortex generator; Swirl flow; CFD simulation; Entropy generation

NOMENCLATURE

\begin{tabular}{|llll}
\hline atm & atmospheric pressure & \multicolumn{2}{c}{ Greek symbols } \\
$B e$ & Bejan number & $\mu$ & dynamics viscosity $(\mathrm{Pa} \mathrm{s})$ \\
$C_{p}$ & specific heat capacity at constant pressure $(\mathrm{J} / \mathrm{kg} \mathrm{K})$ & $\rho$ & density $\left(\mathrm{kg} / \mathrm{m}^{3}\right)$ \\
$F E M$ & finite element method & $\sigma$ & a gap between the computational domain \\
$G$ & reciprocal wall distance & $\theta$ & blade angle \\
$h$ & convection heat transfer coefficient $\left(\mathrm{W} / \mathrm{m}^{2} / \mathrm{K}\right)$ & & \\
$\boldsymbol{I}$ & identity matrix & & \\
$k$ & thermal conductivity $(\mathrm{W} / \mathrm{m} / \mathrm{K})$ & Subscripts \\
$l$ & shift position of the inserted blades $(\mathrm{m})$ & 0 & Smooth pipe without vortex generator \\
$L$ & length of the pipe channel $(\mathrm{m})$ & in & inlet \\
$\dot{m}$ & mass flow rate $(\mathrm{kg} / \mathrm{s})$ & gen & generation \\
$N u$ & Nusselt number & m & mean \\
$p$ & pressure $(\mathrm{Pa})$ & out & outlet \\
$P E C$ & performance evaluation criteria & ref & reference \\
$R$ & universal gas constant $(\mathrm{J} / \mathrm{K} / \mathrm{mol})$ & $\mathrm{W}$ & wall \\
$R e$ & Reynolds number & $\mathrm{x}$ & X-direction \\
$S$ & entropy $(\mathrm{W} / \mathrm{K})$ & $\mathrm{y}$ & y-direction \\
$T$ & temperature $\left({ }^{\circ} \mathrm{C}\right)$ & $\mathrm{z}$ & z-direction \\
$\boldsymbol{u}$ & velocity vector $(\mathrm{m} / \mathrm{s})$ & & \\
$U$ & average velocity $(\mathrm{m} / \mathrm{s})$ & & \\
$V$ & domain volume $\left(\mathrm{m}^{3}\right)$ & & \\
\hline
\end{tabular}

\section{INTRODUCTION}

The need for higher performance of heat exchangers holds broad applications in many fields, such as power and thermal engineering, chemical engineering nuclear power, solar energy thermal transfer, etc. Therefore, technologies focusing on the enhancement of heat transfer in heat exchangers has always been a hot topic. One of the methods that have widely been adapted and investigated in the literature is the use of augmentation techniques. Such methods proved to bring compact designs and substantial energy savings. Recently, serious attempts have been made to introduce different augmentation techniques to enhance the heat transfer process in the heat exchanger devices. The heat transfer augmentation techniques can be classified into active and passive methods, depending on whether extra power is needed for the enhancement process or not [1]. 
The use of vortex generators is widely regarded as one of the effective techniques to enhancement heat transfer, where many researchers have investigated such methods both experimentally and numerically. Patil and Tandel [2] studied several geometries and different types of vortex generators as passive technique applications. They also provided a comprehensive review of the effects of orientation of the inserts on the friction factor and convective heat transfer coefficient.

Among the various augmentation techniques, the insertion of a twisted tape swirl generator is regarded as one of the practical methods. Such augmentation technique causes notable enhancement in the thermal characteristics by reducing the thermal boundary layer thickness in the flow regime [3-5]. Bhuiya et al. [6] experimentally studied the thermal and hydraulic performances of perforated double counter twisted tape inserts in a heat exchanger tube. The results showed a significant increase in both the heat transfer rate as well as the friction factor, where the change in heat transfer rate and friction factor were found to be 80 to $290 \%$ and 111 to $3535 \%$ in comparison to the empty tube values, respectively. Roohi et al., [7] investigated the thermo-hydraulic performance of a rectangular microchannel with longitudinal vortex generators, and in another study [8] they investigated the effect of nanofluids in a microchannel with vortex generator, where the performance-enhanced from $2.5-29 \%$ using $\mathrm{Al}_{2} \mathrm{O}_{3}$ nanoparticles. Among the other simple structure, low cost and easy installment augmentation techniques that are widely adopted are a ring, small pipe, and delta wing vortex generators, which were reported to enhance the rate of heat transfer in a circular tube [9-14].

Another type of augmentation technique that has been investigated by Huang at al. [15] is the inset of a porous material. The researcher confirmed that the use of such materials enhanced the heat transfer characteristics using the same pumping power. The effect of porosity, spacer length, pore type, and clearance were among the different parameters that they investigated. Recently, other kinds of inserts have also been investigated, such as vortex rods [16], mesh cylinders [17], cylindrical blade tube inserts [18], multiple conical inserts [19], conical strip inserts [20]. They have been applied and examined for heat transfer enhancement in the pipe flow.

One of the efficient passive methods to enhance the thermal characteristics is the propeller-type vortex generator insert at the air intake of the flow passage. The merits of such a system are to reduce equipment investment as well as decrease the volume size compared with its counterpart of the plain passage. A propeller-type vortex generator insert brings several advantages such as enhancing the thermal characteristics due to swirl flow generation, which is generally referred to as vortical flow [21] as well as the low cost and both easy fabrication and maintenance. The swirl flows can be categorized into two types: non-decaying (steady) and decaying (unsteady) [22]. The swirl is continuous for the non-decaying case, while it is not continuous for the latter. Recently, Bali and Sarac [23] experimentally investigated the heat transfer and the pressure drop characteristics for decaying turbulent swirl flow in a circular pipe with a propeller-type vortex generator.

There has been a limited number of studies in the literature that investigate the relationship between entropy generation in swirl pipe and swirled intensity [24-27]. The reported work aimed at investigating such a relationship at constant Reynolds number and fluid-wall temperature difference. It was found that the relationship between entropy generation, swirl number, and temperature difference is nonlinear. Using the entropy generation minimization method, the field of synergy principle, and entransy dissipation extreme principle, Lie et al., [27] reported the justification of the augmentation techniques applied for heat transfer enhancement. In their work, they reported the existence of a research gap between theories and techniques in convective heat transfer enhancement, where further theoretical studies are needed to promote technique developments in this area.

In this study, the propeller-type vortex angles generator inserts with four blades at different blade angles, which are located at the intake of the tube, have been investigated numerically. The effects of the blade angles on the vortex formation, the heat transfer enhancement, and consequently the entropy generation of suggested vortex generators are investigated.

\section{MATHEMATICAL MODEL}

A 3-D depiction of the flow channel with the augmented vortex generator is shown in Figure 1. The vortex generator is shifted with a distance $l$, of $5 \mathrm{~cm}$ for all considered configurations. The pipe length, $L$, and diameter $D$ are fixed at $1.978 \mathrm{~m}$ and 0.0547 $\mathrm{m}$, respectively. The tilt angle, $\theta$, is shown in Figure 1-(b), where $\theta=0^{\circ}$ and $\theta=90^{\circ}$ mean the flow direction is perpendicular to the blades, and parallel to the flow direction, respectively. 


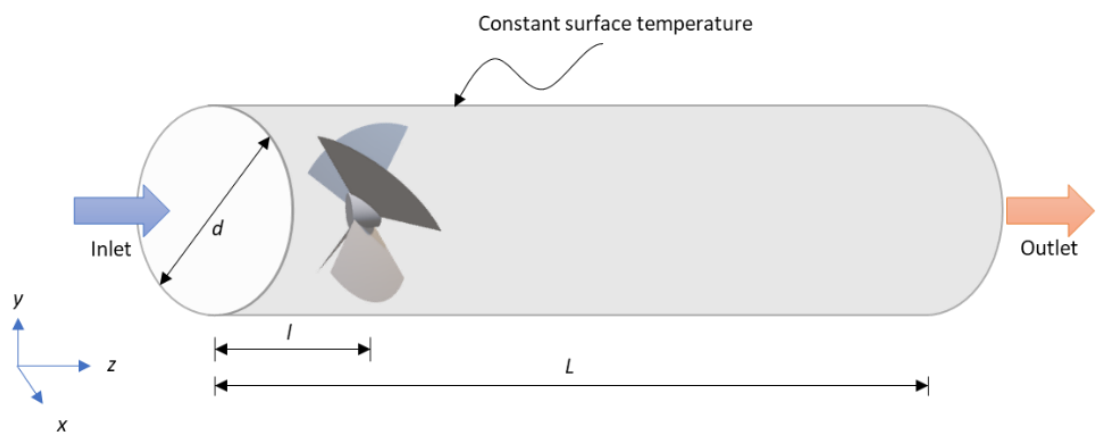

(a)

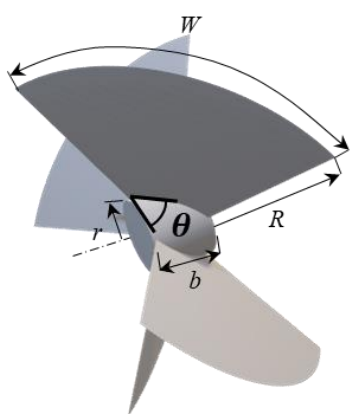

(b)

Figure 1: Schematic depiction of the mathematical model: (a) the pipe with the augmented vortex generator, (b) the tilt angle of the blades.

In this study, four different configurations are considered. The values of the parametric geometry considered in this study are given in Table 1. These values are selected to match the experimental setup given in [28,29].

Table 1: The values of the geometrical parameters.

\begin{tabular}{|c|c|c|r|r|}
\hline $\boldsymbol{\theta}\left(^{\circ}\right)$ & $\boldsymbol{b}(\mathbf{m m})$ & $\boldsymbol{W}(\mathbf{m m})$ & $\boldsymbol{r}(\mathbf{m m})$ & $\boldsymbol{R}(\mathbf{m m})$ \\
\hline $\mathbf{1 5}$ & 2.104 & 89.405 & 5.21 & 26.71 \\
\hline $\mathbf{3 0}$ & 4.534 & 87.419 & 5.94 & 27.44 \\
\hline $\mathbf{4 5}$ & 7.853 & 83.295 & 7.64 & 29.14 \\
\hline $\mathbf{6 0}$ & 13.6 & 74.870 & 12.02 & 33.52 \\
\hline
\end{tabular}

\subsection{Governing equations}

The governing equation that describes the physical characteristics of the problem are mass, momentum, and energy balances. The flow is assumed to be weakly compressible, turbulent, and non-isothermal. The steady flow continuity equation, for the flow domain, is given as follows:

$$
\nabla \cdot(\rho \boldsymbol{u})=0
$$

where $\rho$ is the density and $\boldsymbol{u}$ is the velocity vector in $x, y$ and $z$ directions. The momentum balance equation is given by ReynoldsAveraged Navier-Stokes equations (RANS), and the model that has been implemented in this study is the algebraic yPlus model which is suitable for internal flows. More discussion about the reasons for selecting this model in comparison to the widely known transport equation models such as the $k-\varepsilon$ or the SST is provided is provided in section 3 . The RANS model is given in the following set of equations:

$$
\begin{gathered}
\rho(\boldsymbol{u} \cdot \nabla \boldsymbol{u})=-\nabla p+\nabla \cdot\left(\left(\mu+\mu_{T}\right)\left(\nabla \boldsymbol{u}+(\nabla \boldsymbol{u})^{T}\right)-\frac{2}{3}\left(\mu+\mu_{T}\right)(\nabla \cdot u) \boldsymbol{I}\right) \\
R e_{w}=\frac{\rho \boldsymbol{u} l_{w}}{\mu} \\
\nabla G \cdot \nabla G+\sigma_{w} G(\nabla \cdot \nabla G)=\left(1+2 \sigma_{w}\right) G^{4} \\
l_{w}=\frac{1}{G}-\frac{l_{r e f}}{2}
\end{gathered}
$$

where $\mu_{T}$ is the turbulent dynamic viscosity, $\boldsymbol{I}$ is the identity matrix, $R e_{w}$ is the Reynolds number near the wall, $l_{w}$ is the wall distance, $l_{r e f}$ is the reference length scale, which is set to one-tenth of the shortest side of the geometry. $G$ in the third equation is the reciprocal wall distance and $\sigma_{w}$ the smallest gap between the computational domain and the physical wall. This parameter is assumed to be half the height of the mesh adjacent to the wall. The steady energy balance equation is given in the following form:

$$
\rho C_{p} \boldsymbol{u} \cdot \nabla T=\nabla \cdot(k \nabla T)+\Phi
$$

where $C p$ is the specific heat at constant pressure, $k$ the thermal conductivity, $T$ the temperature and $\Phi$ is the viscous dissipation function given by the following expression:

$$
\Phi=2\left[\left(\frac{\partial u}{\partial x}\right)^{2}+\left(\frac{\partial v}{\partial y}\right)^{2}+\left(\frac{\partial w}{\partial z}\right)^{2}\right]+\left(\frac{\partial u}{\partial y}+\frac{\partial v}{\partial x}\right)^{2}+\left(\frac{\partial w}{\partial y}+\frac{\partial v}{\partial z}\right)^{2}+\left(\frac{\partial u}{\partial z}+\frac{\partial w}{\partial x}\right)^{2}
$$




\subsection{Boundary conditions}

The following boundary conditions were implemented for the mathematical model. At the entrance of the pipe inlet:

$$
u=v=0, \quad w=W_{i n}, \quad T=T_{i n}
$$

where $W_{\text {in }}$ is the inlet velocity in the $z$-direction and it is fixed by matching the considered Reynolds numbers. The inlet temperature $T_{\text {in }}$ is kept at $22^{\circ} \mathrm{C}$ to match the experimental data. The outlet boundary conditions are given as follows:

$$
\frac{\partial u}{\partial z}=\frac{\partial v}{\partial z}=\frac{\partial w}{\partial z}=0, \quad \frac{\partial T}{\partial z}=0
$$

The boundary conditions on the wall surface is given by:

$$
u=v=w=0, \quad T=T_{w}
$$

The wall surface temperature of the pipe is fixed at $100^{\circ} \mathrm{C}$. No-slip boundary condition was implemented over the blade's surfaces

\subsection{Material properties}

The material properties that were used in the numerical model are expressed as follows. The density of the air is given using the ideal gas equation as:

$$
\rho=\frac{p}{R T}
$$

where $R$ is the air gas constant. Forth-order degree polynomials are used to determine the specific heat, the thermal conductively, and the dynamic viscosity, respectively, as follows:

$$
\begin{gathered}
C_{p}=1047.64-0.37 T^{1}+9.45 \times 10^{-4} T^{2}-6.02 \times 10^{-7} T^{3}+1.29 \times 10^{-10} T^{4} \\
k=-0.0022+1.15 \times 10^{-4} T^{1}-7.90 \times 10^{-8} T^{2}+4.12 \times 10^{-11} T^{3}-7.44 \times 10^{-15} T^{4} \\
\mu=-8.38 \times 10^{-7}+8.36 \times 10^{-8} T^{1}-7.69 \times 10^{-11} T^{2}+4.64 \times 10^{-14} T^{3}-1.07 \times 10^{-17} T^{4}
\end{gathered}
$$

Further details about the material properties could be found in [30].

\subsection{System performance}

In order to evaluate the performance of the system, the convection heat transfer coefficient $(h)$ and the Nusselt number $(N u)$ need to be first evaluated on the wall surface. The convection heat transfer coefficient is defined as follows:

$$
h=\frac{-k \frac{\partial T}{\partial \vec{n}} \cdot \vec{n}}{T-T_{m}}
$$

where $\vec{n}$ is the normal unit vector perpendicular to the surface and $T_{m}$ the mean temperature inside the flow domain, which changes across the $z$-direction. The local Nusselt number is calculated according to the following formula:

$$
N u=\frac{h D}{k}
$$

where $D$ is the diameter of the pipe. To calculate the average value of the Nusselt number $(\overline{N u})$ over the entire volume $(V)$, the following expression is implemented:

$$
\overline{N u}=\frac{1}{V} \int N u d V
$$

The two factors that are causing the irreversibilities, i.e., entropy generation, in the flow domain; are the heat transfer process and the viscous dissipation in the fluid motion. The volumetric rate of entropy generation can be evaluated according to the following expression:

$$
\dot{S}_{\text {gen }}^{\prime \prime \prime}=\dot{S}_{g e n_{T}}^{\prime \prime \prime}+\dot{S}_{g e n_{F}}^{\prime \prime \prime}=\frac{k}{T^{2}}(\nabla T)^{2}+\frac{\mu}{T} \Phi
$$

where $\dot{S}_{g e n_{T}}^{\prime \prime \prime}$ is the entropy generation due to heat transfer, $\dot{S}_{g e n_{F}}^{\prime \prime \prime}$ the entropy generation due to viscous dissipation $\Phi$. The total entropy generation rate can be given by integrating (15) over the flow domain as follows: 


$$
\dot{S}_{g e n}=\int \dot{S}_{g e n}^{\prime \prime \prime} d V
$$

Bejan number $(B e)$ is used to define the ratio of irreversibility due to heat transfer to the total irreversibility of the flow, i.e., heat transfer and viscous dissipation. The Bejan number is given according to the following expression:

$$
B e=\frac{\dot{S}_{g e n_{T}}^{\prime \prime \prime}}{\dot{S}_{g e n_{T}}^{\prime \prime}+\dot{S}_{g^{\prime \prime n} n_{F}}^{\prime \prime}}
$$

The overall performance evaluation criteria $(P E C)$ of the system, as suggested by Webb [31] is given by:

$$
P E C=\frac{N u / N u_{0}}{\left(f / f_{0}\right)^{1 / 3}}
$$

where $f$ is the friction factor coefficient defined as:

$$
f=\frac{2 \Delta p D}{\rho U^{2} L}
$$

where $\Delta p$ is the pressure drop between the inlet and the outlet of the pipe channel, $U$ is the average velocity, and $N u_{0}$ and $f_{0}$ given in equation (18) denote to the average Nusselt number and friction factor of a corresponding smooth pipe without a vortex generator.

\section{NUMERICAL PROCEDURE AND MODEL VALIDATION}

The mathematical model described in equations (1)-(3), were solved by a Galerkin finite element method (FEM) in COMSOL Multiphysics software [30]. The model is solved using segregated stationary solvers where the convergence criterion was set to $1 \times 10^{-4}$ for the relative tolerance, and Algebraic multigrid solvers were used for the linear systems.

Before selecting the yPlus turbulence model, the SST turbulence model was tested at different Re and compared with the experimental data. Although the SST model is considered as a superior model in comparison to the algebraic turbulence model. Nevertheless, for this problem, i.e., internal flow, the results of the SST model significantly deviated from the experimental results at large $R e$ when compared to the yPlus. For the highest $R e$, the difference was around 39\% for the SST model, while it was only $8 \%$ for the yPlus model. Therefore, the yPlus model has been selected to carry our calculation for the current work.

A grid independence study conducted to assure that the solution is independent of the mesh refinements. A summary of the results for three different grids for $\theta=30^{\circ}$ is shown in Table 2, where the relative error is shown for each case in comparison to the solution given on the finest mesh. The finest mesh configuration, where the change in the solution varied from 1-6\% for the

\begin{tabular}{|c|c|c|c|c|c|}
\hline & $\begin{array}{l}\text { Element } \\
\text { number }\end{array}$ & $T_{o}\left[{ }^{\circ} \mathrm{C}\right]$ & $\begin{array}{l}\text { Relative } \\
\text { error } \%\end{array}$ & $\Delta P[P a]$ & $\begin{array}{l}\text { Relative } \\
\text { error } \%\end{array}$ \\
\hline 1 & 417387 & 60.2 & $6 \%$ & 316.2 & $10 \%$ \\
\hline 2 & 959840 & 62.2 & $1 \%$ & 326.6 & $7 \%$ \\
\hline 3 & 3201222 & 63.3 & - & 352.9 & - \\
\hline
\end{tabular}
temperature field, $7-10 \%$ in the pressure drop. Therefore, the configurations of the finest mesh were selected to carry the rest of the parametric study.

Table 2: Grid independence study.

The finest grid for the configuration with $\theta=30^{\circ}$ is shown in Figure 2. A very fine grid near the blades inside the flow domain are used in addition to boundary layer elements near the walls to capture a better flow characteristic in the vicinity of these boundaries. 


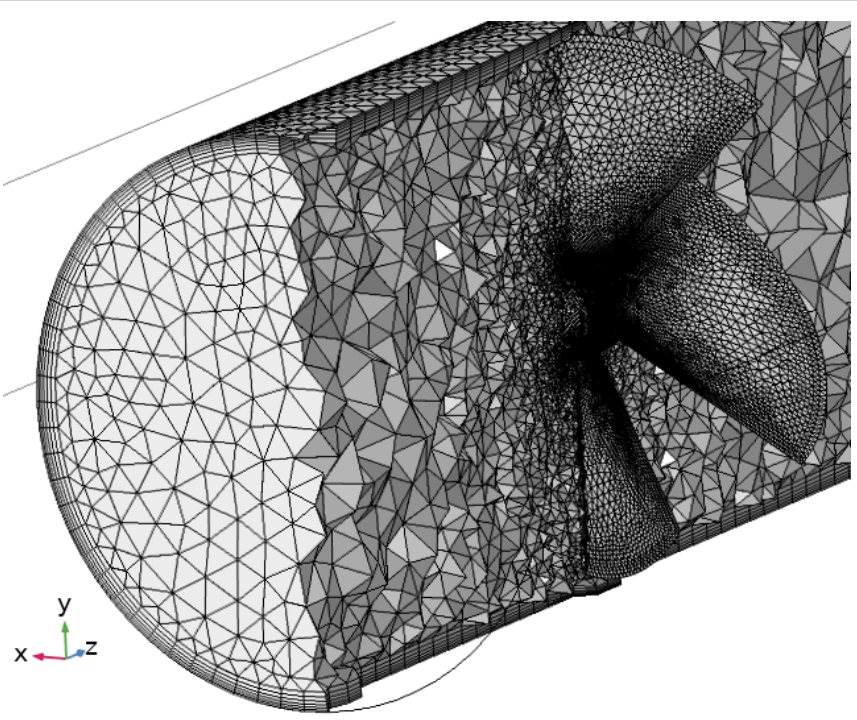

Figure 2: Depiction of the finest grid used in the current study for $\theta=30^{\circ}$.

Figure 3 shows a comparison between the current results and the experimental data [29] for the average $\overline{N u}$ vs. $R e$. The solid lines represent the results predicted by the model, while the dashed lines represent the results obtained from the experiment. The model developed in this study produced results that are close to the experiment, where the relative error between the model and the experiment is well below $10 \%$. The only exception case was for the highest $R e=30000$ and $\theta=15^{\circ}$. Still, the relative error was about $14 \%$ in this extreme situation. Moreover, for the case of a smooth pipe, the figure shows a comparison between model and experiment as well as the Dittus-Boelter equation [32]. The values of the model and the Dittus-Boelter equation are in very close agreement until the highest $R e$ where the model gives slightly smaller results in comparison to the Dittus-Boelter equation.

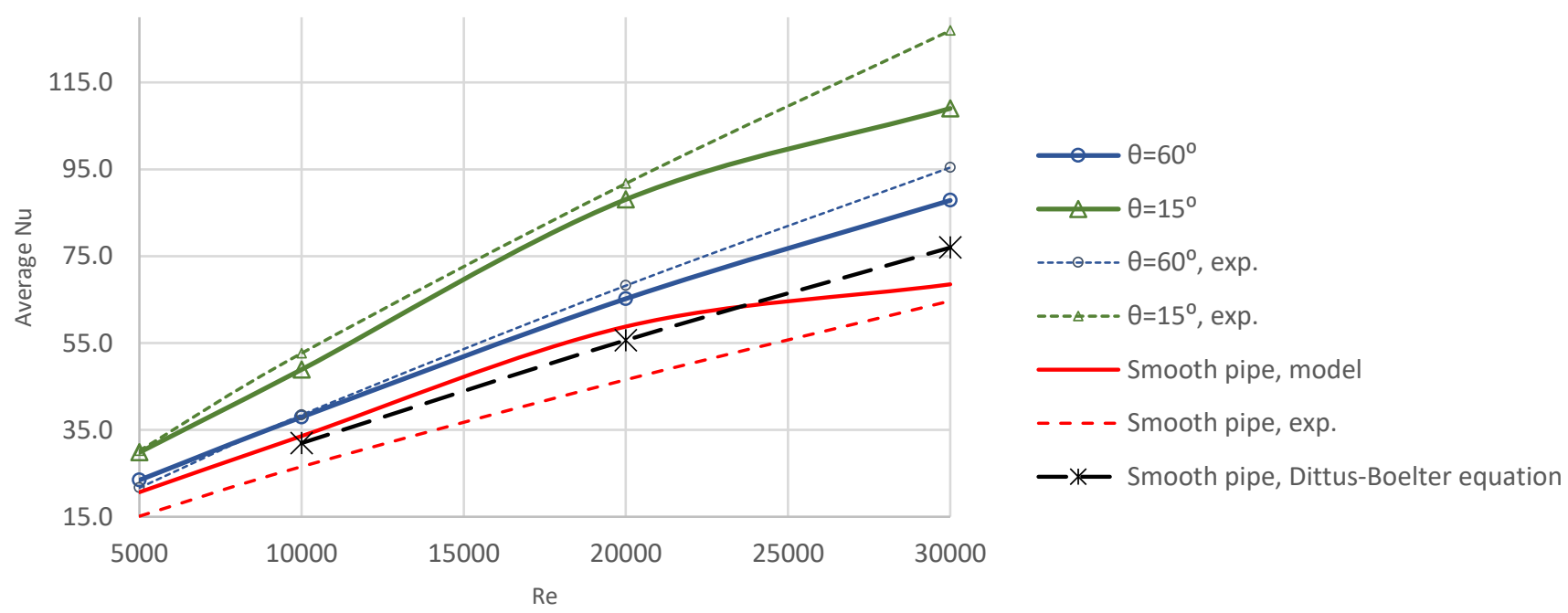

Figure 3: Average Nu (model and experiment) vs. Re for the different blade angles.

\section{RESULTS AND DISCUSSION}

In this study, the influence of the four-blade angles over the heat transfer and fluid flow characteristics were investigated, i.e., $\theta=15^{\circ}, 30^{\circ}, 45^{\circ} \& 60^{\circ}$. For each blade angle, four different flow rates were investigated, i.e., $R e=5000,10000,20000 \&$ 30,000. The results for the different augmented vortex generators are compared to both experimental and numerical results of a smooth pipe with no vortex generator.

The average temperature at the outlet of the pipe channel is shown in Figure 4. A sharper decay in the temperature is noticed as $R e$ is increased from 5000 to 10000 in comparison to the higher $R e$. The augmentation of the vortex generator increased the outlet temperature, which implies an enhancement in the heat transfer process. The highest temperature is achieved for the smallest 
$\theta$ since this configuration caused the highest swirling effect. The intensity of the swirling phenomenon decreased by increasing $\theta$, which can be better seen in the following figure.

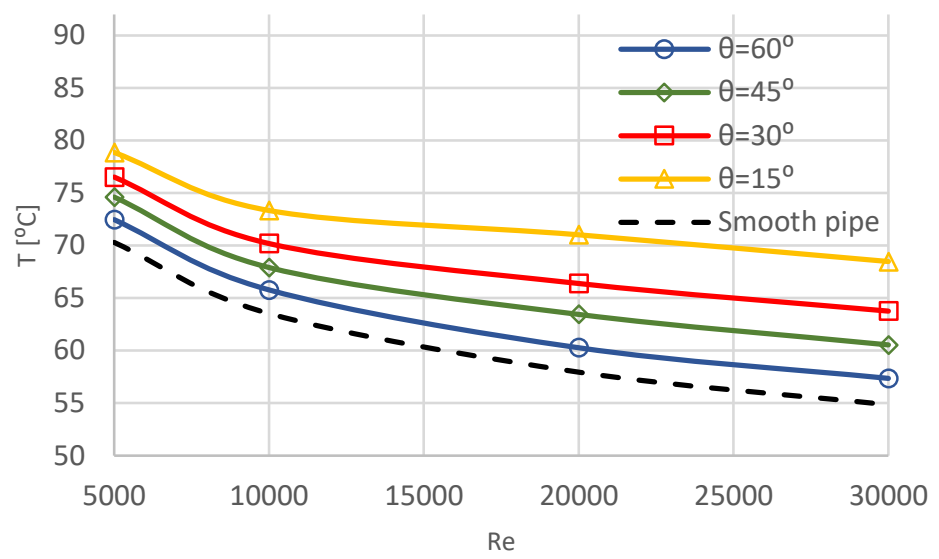

Figure 4: Outlet temperature vs. Re for the different blade angles.

To show the effect of the blade angles on the 3-D field solution, two Re are considered $5000 \& 20000$. The considered $R e$ show the characteristic of the solution at relatively low and high flow rates. Since the deviation between the solution and the experimental data was much smaller for the case of $R e=20000$ in comparison to $R e=30000$, therefore the former $R e$ was picked to represent the high flow rate.

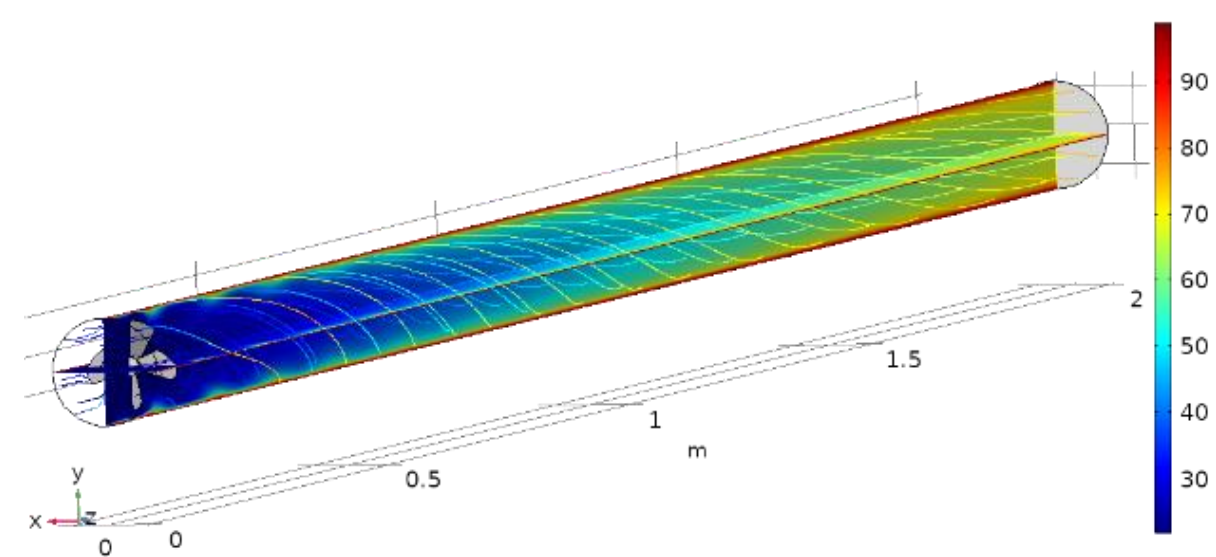

(a)

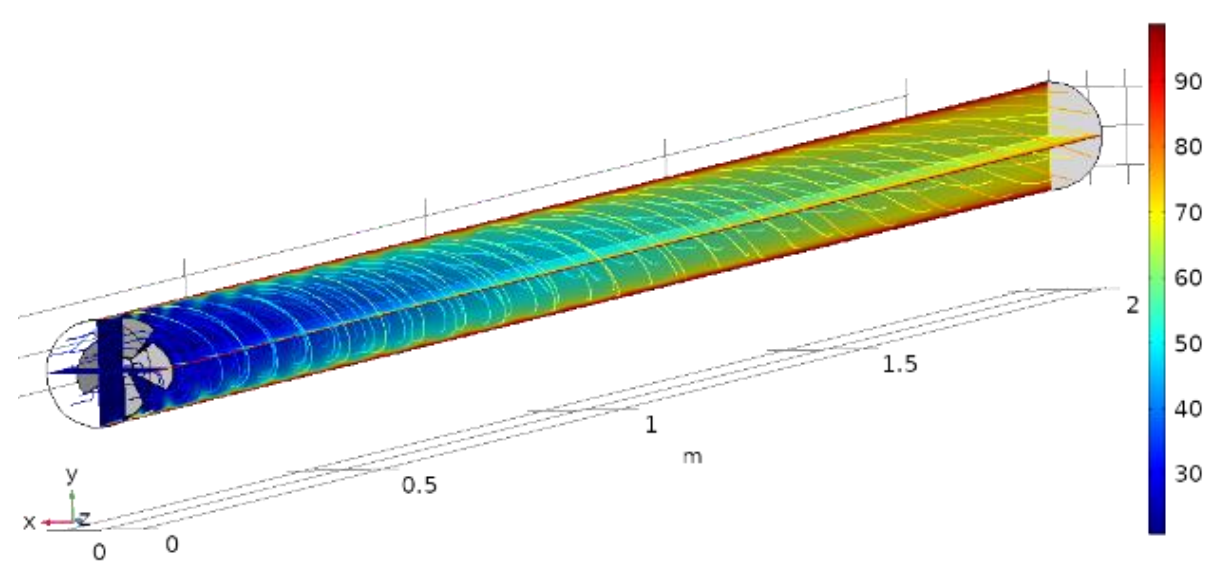


(b)

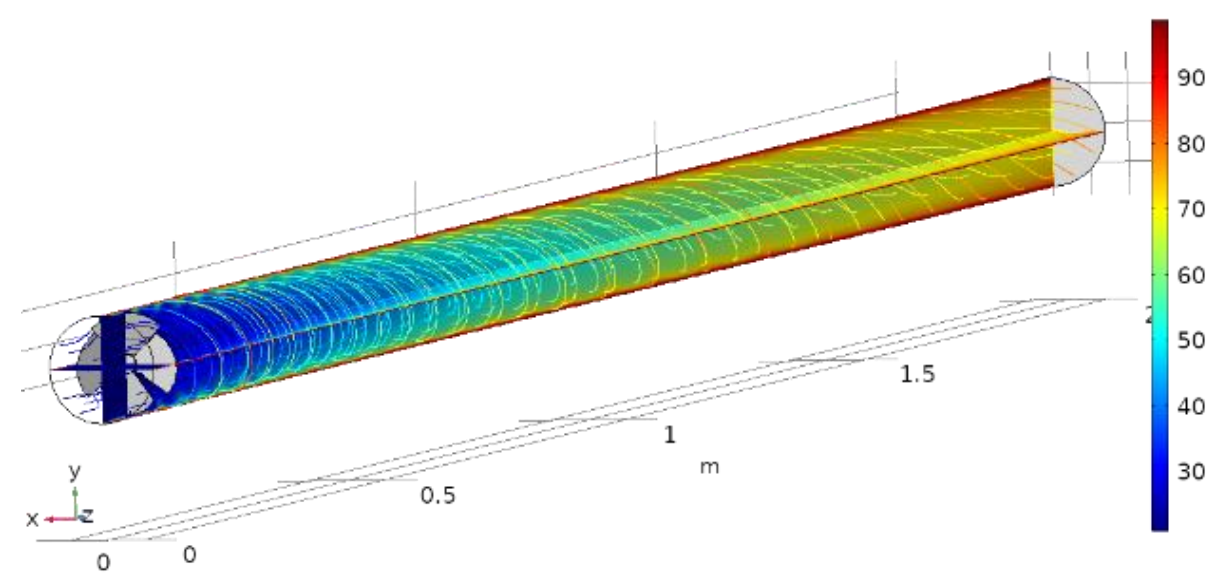

(c)

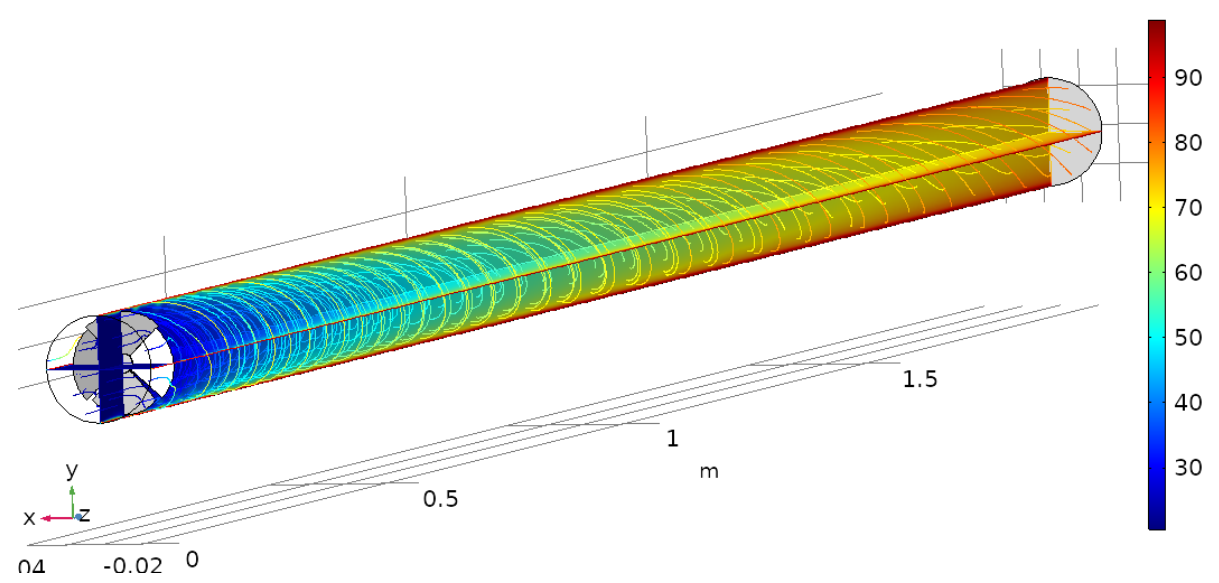

(d)

Figure 5 shows the temperature profile inside the pipe channel for the different $\theta$ at $R e=5000$. Decreasing $\theta$ increased the intensity of the vorticity of the flow as discussed earlier and as can be seen in the streamline plots. Another observation that can be made here is that decreasing $\theta$ enhanced the heat transfer process as the outlet temperature increased for $\theta=15^{\circ}$.

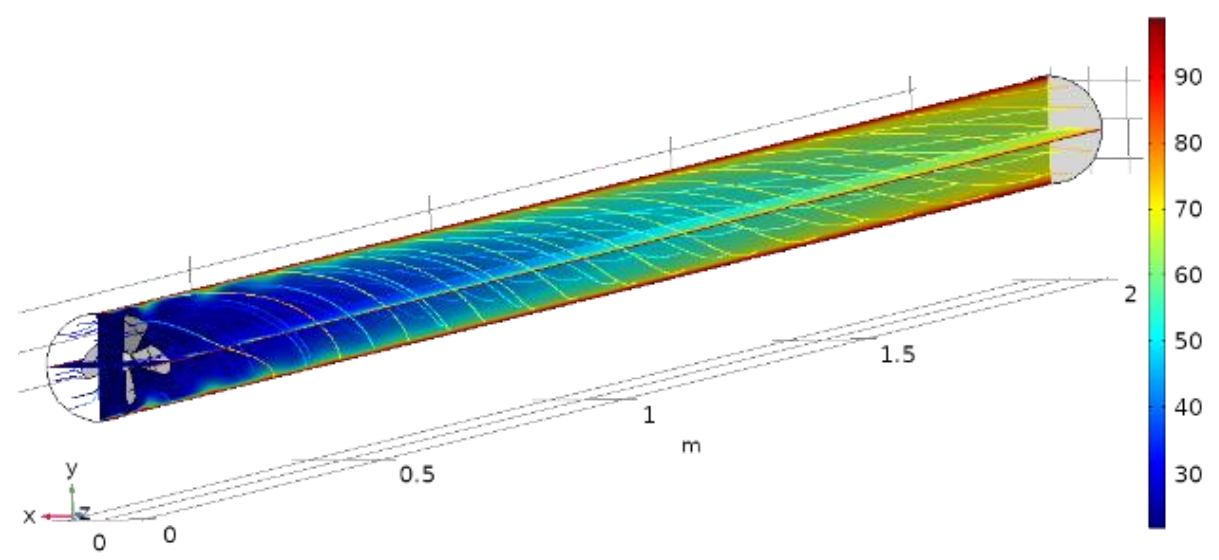

(a) 


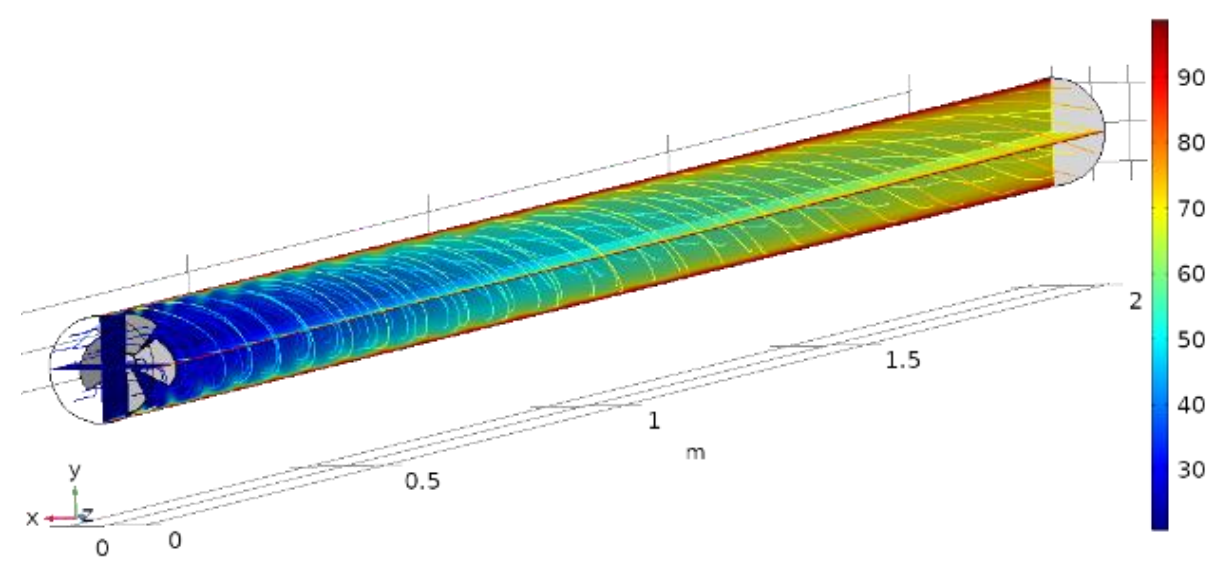

(b)

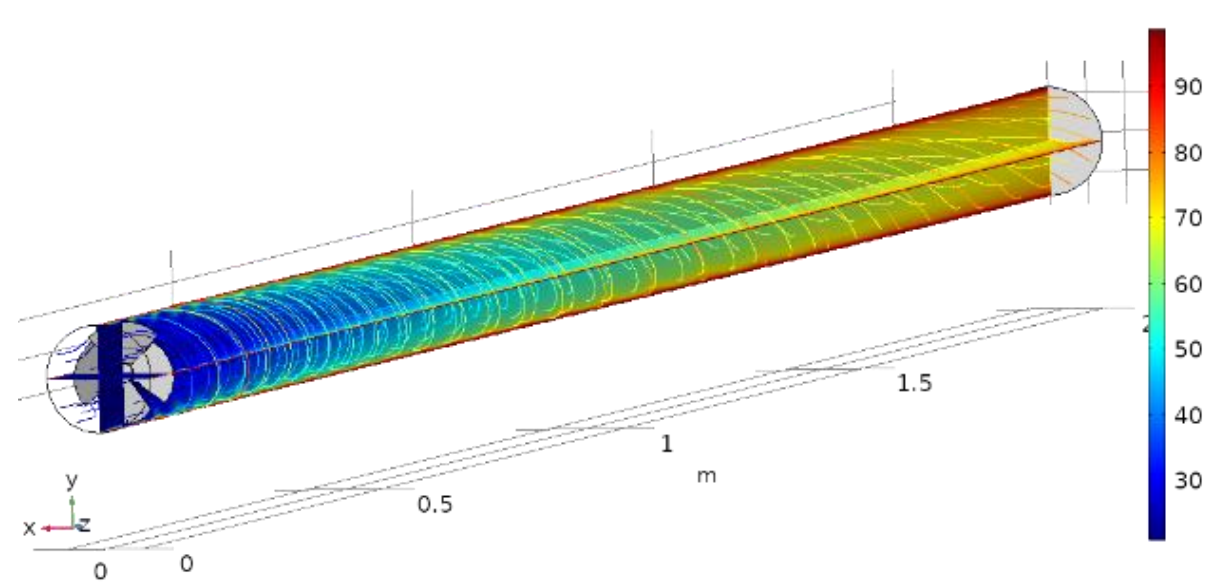

(c)

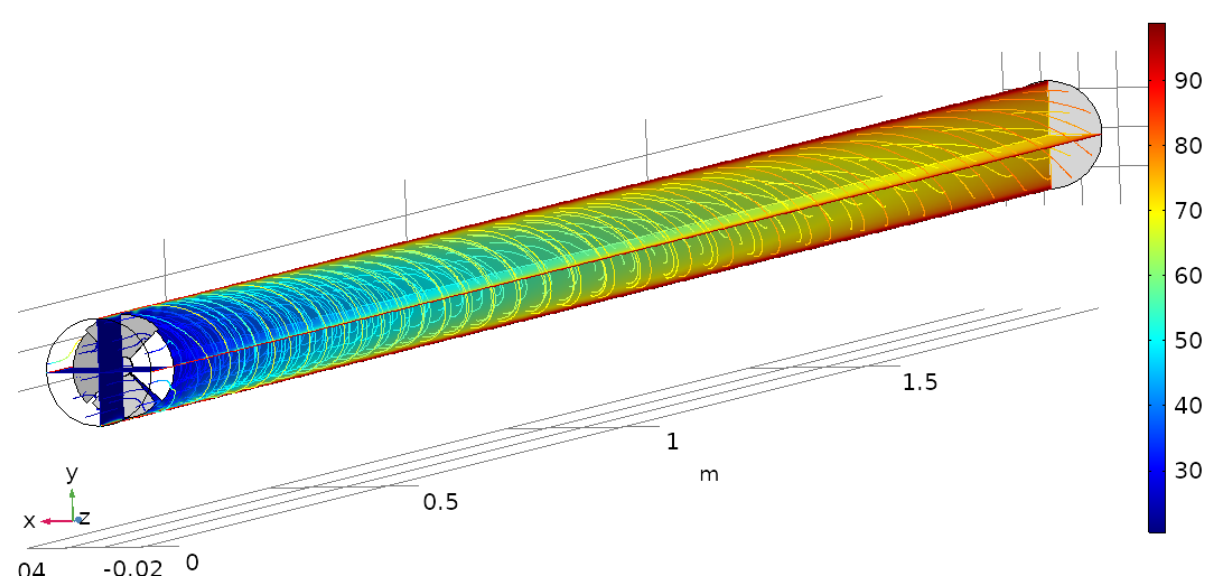

(d)

Figure 5: Temperature profile with $\operatorname{Re}=5000$, (a) $\theta=60^{\circ}$, (b) $\theta=45^{\circ}$, (c) $\theta=30^{\circ}$, (d) $\theta=15^{\circ}$.

The temperature profile for the case of $R e=20000$ is shown in 


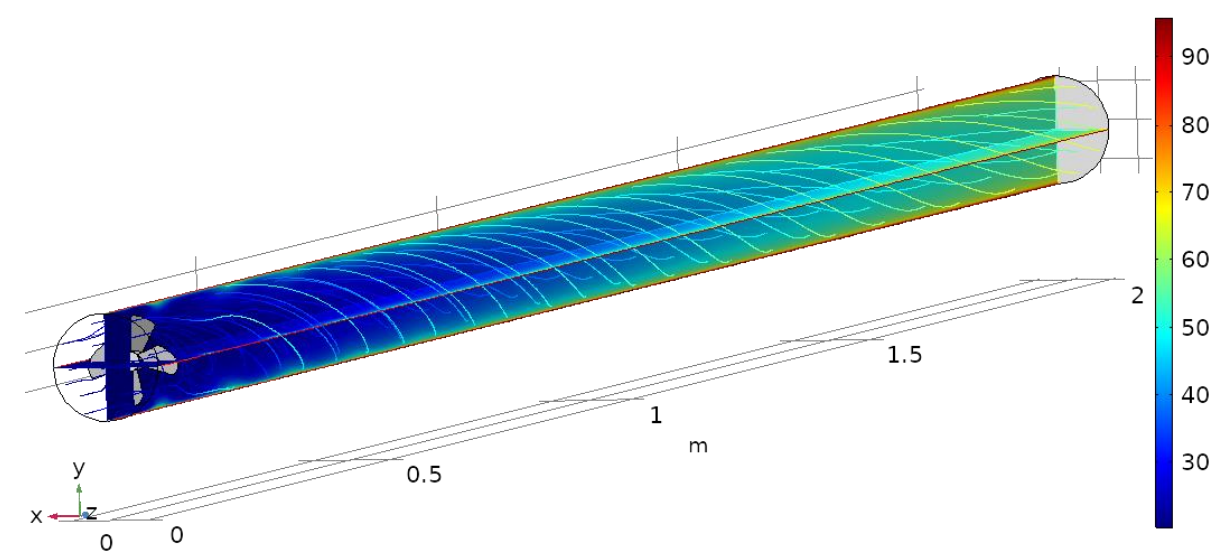

(a)

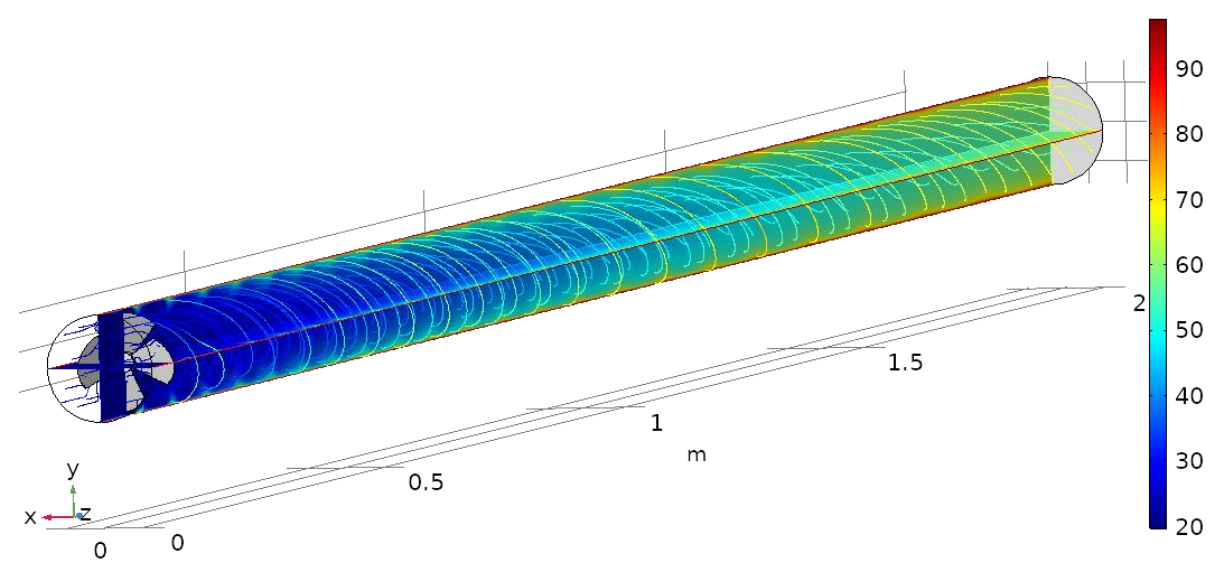

(b)

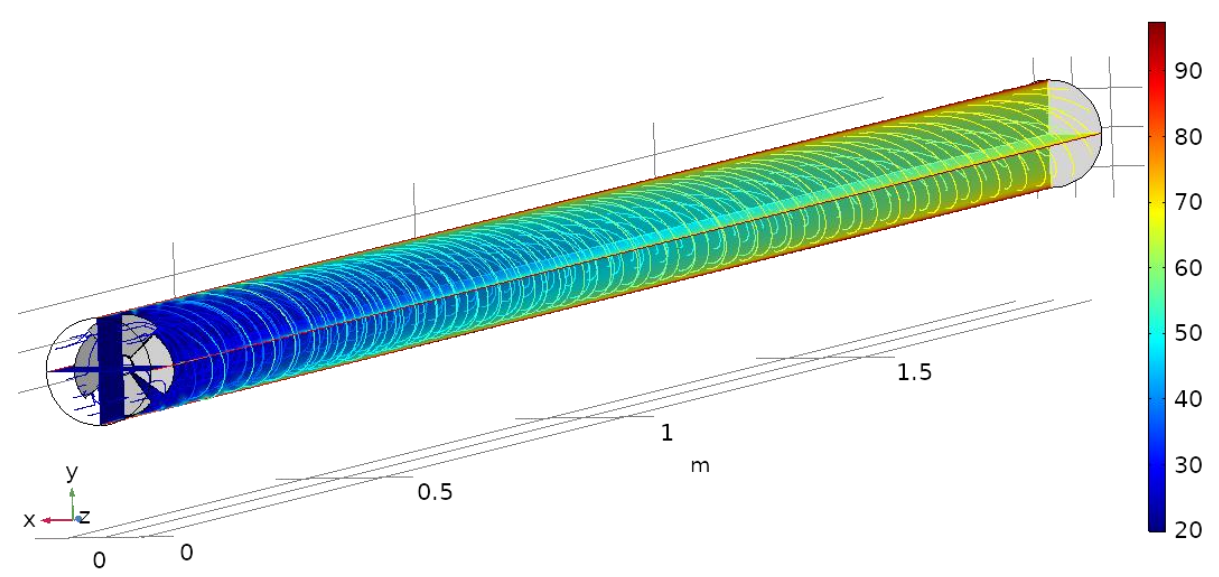

(c) 


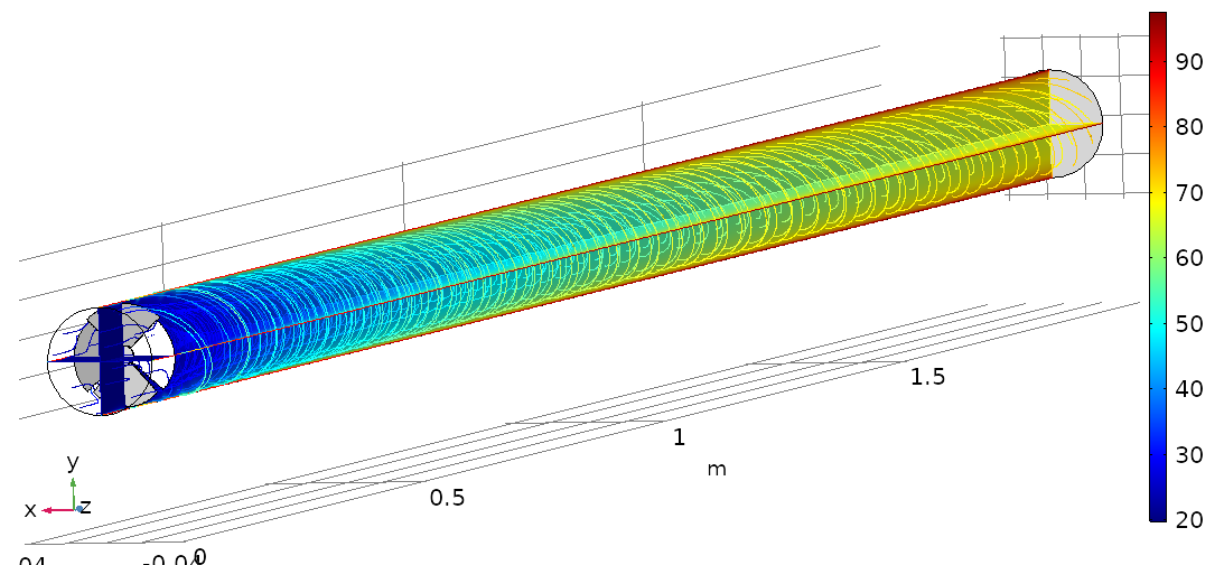

(d)

Figure 6. Increasing the flow rate decreased the interaction time between the fluid and the hot surfaces, which resulted in decreasing the outlet temperature in comparison to $R e=5000$. Also, decreasing $\theta$ from $60^{\circ}$ to $15^{\circ}$ caused $11^{\circ} \mathrm{C}$ increment in the outlet temperature. It is noticed that decreasing $\theta$ by $15^{\circ}$ increased the temperature on average by $5 \%$.

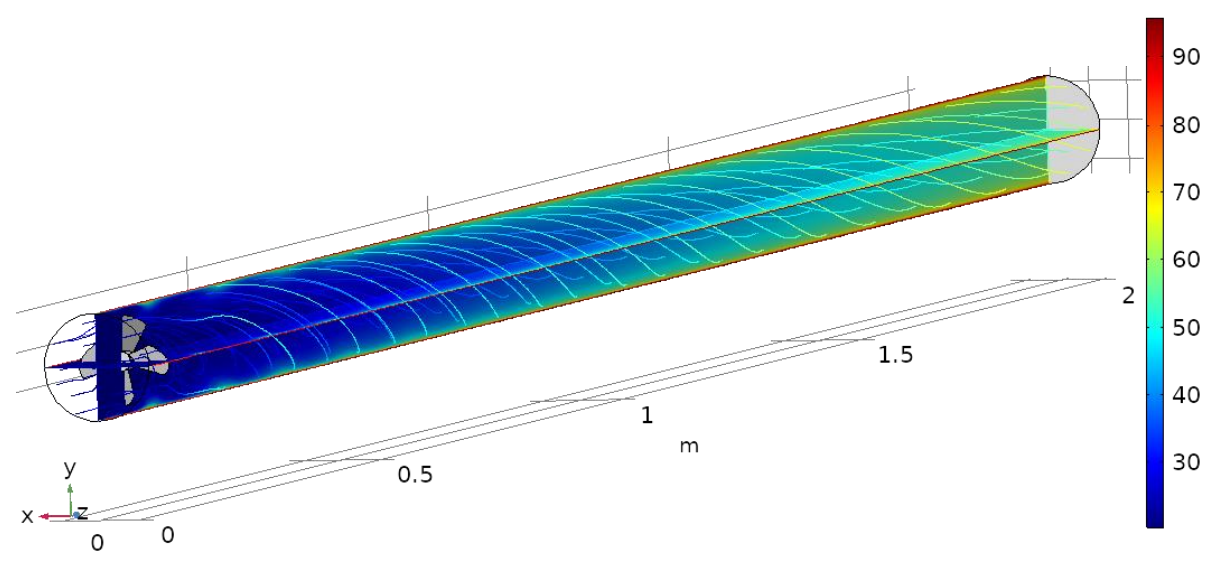

(a)

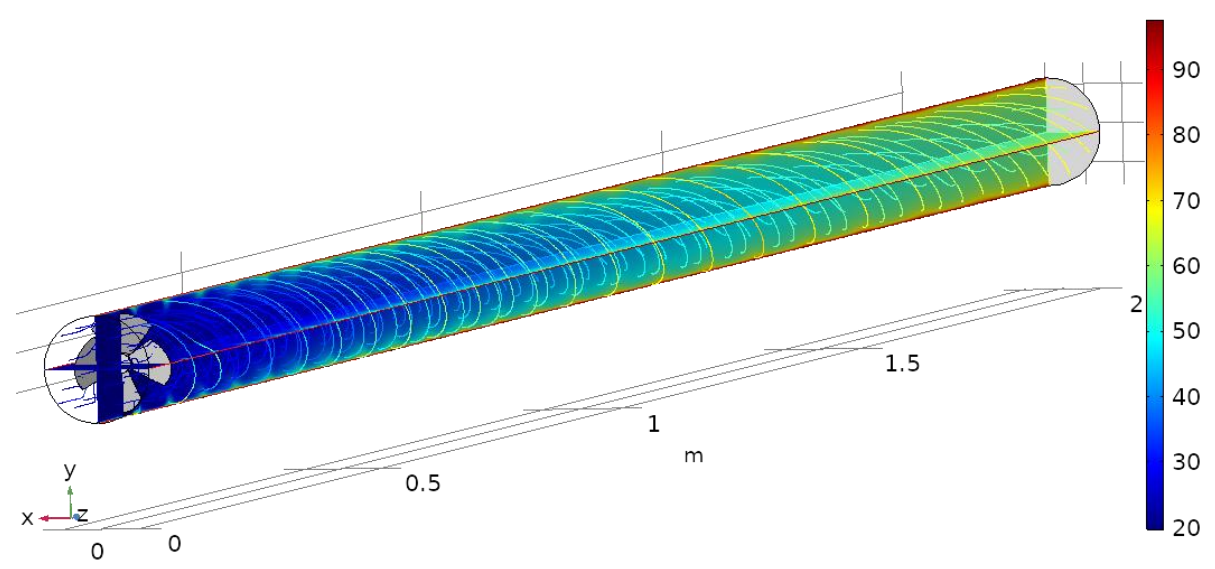

(b) 


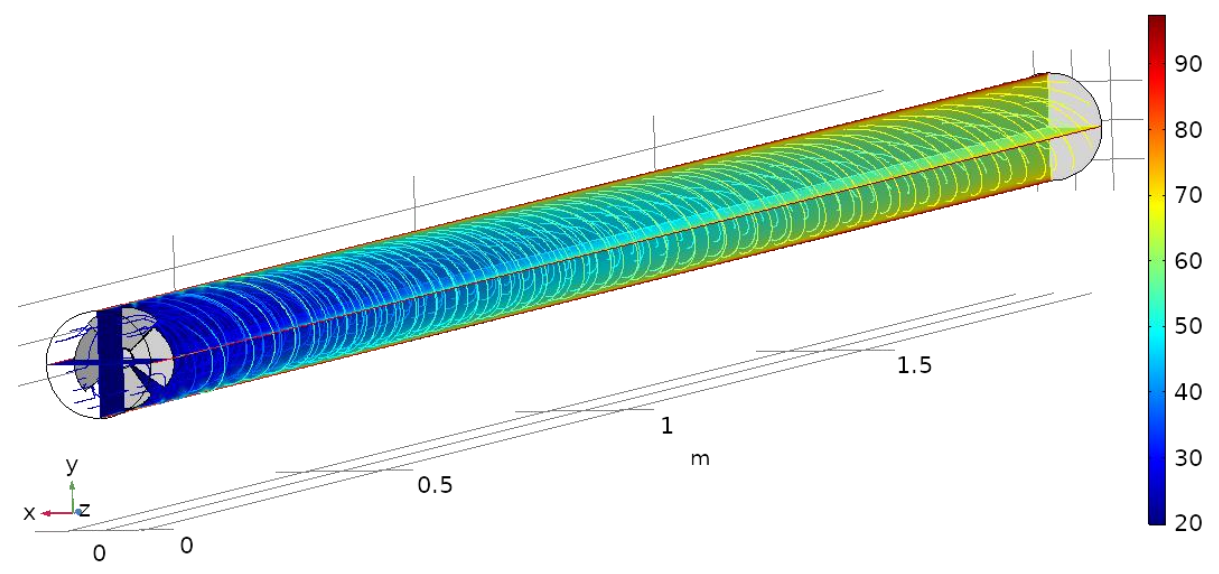

(c)

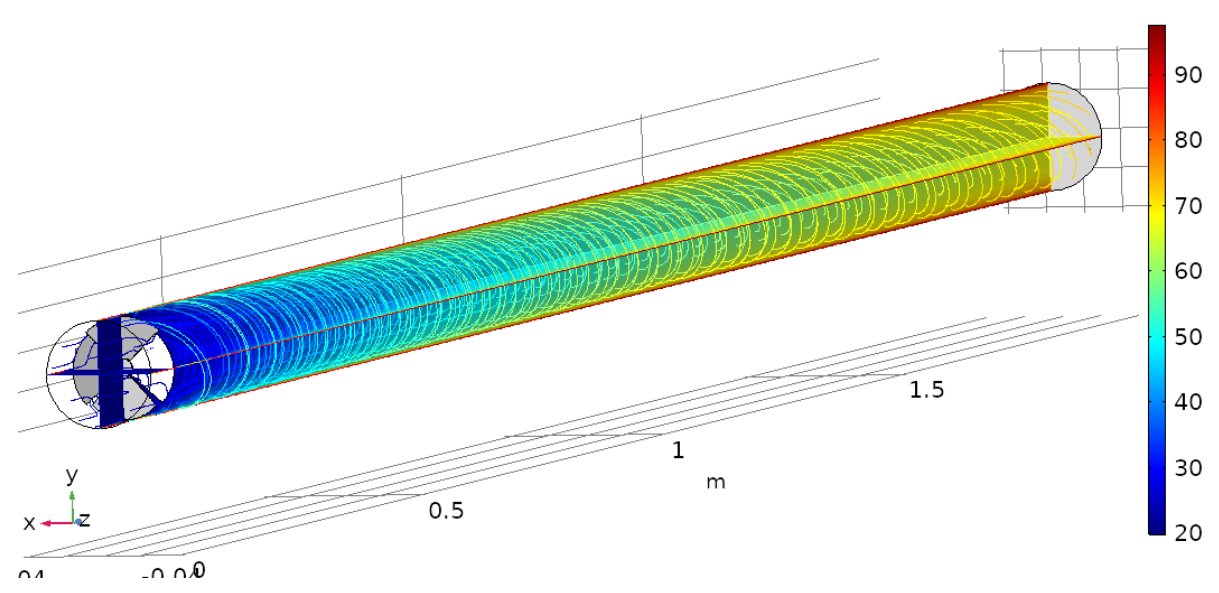

(d)

Figure 6: Temperature profile with $\operatorname{Re}=20000$, (a) $\theta=60^{\circ}$, (b) $\theta=45^{\circ}$, (c) $\theta=30^{\circ}$, (d) $\theta=15^{\circ}$.

The local heat transfer coefficient $(h)$ on the surface of the pipe which is calculated using equation (12) is shown in Figure 7 and Figure 8 for $R e$ of 5000 and 20000, respectively. It is worth mentioning that the solution presented in these two figures are shown for the first $0.5 \mathrm{~m}$ length of the pipe in order to have a clearer view of the effect of these vortex generators. For the case of $R e$ of 5000 (Figure 7), several observations are made. First, it is noticed that the swirling phenomenon caused by the inserted vortex generator leads to a cyclic behavior of $h$, where the frequency increases by decreasing $\theta$. The second observation is that a sudden spike in $h$ is experienced just behind the vortex generator and the intensity of this spike again increases by decreasing $\theta$.

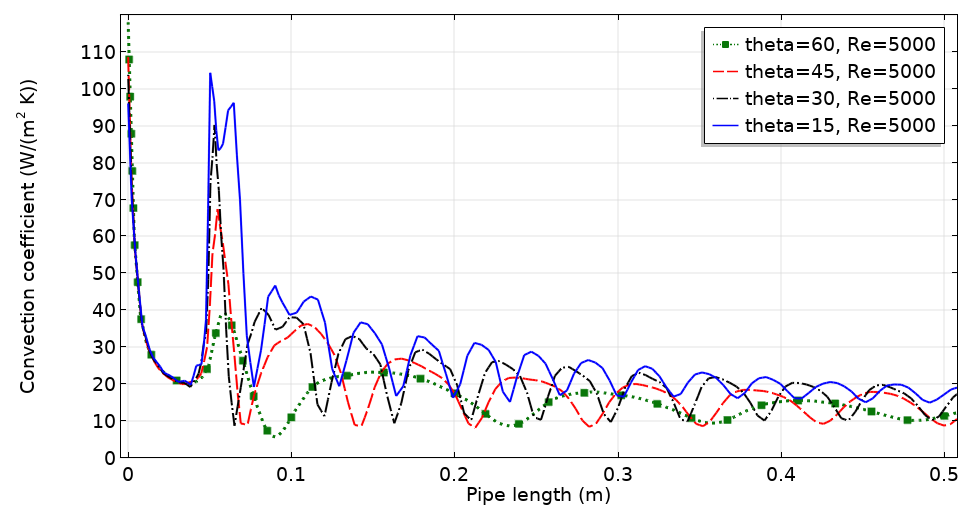

Figure 7: Convection heat transfer coefficient along the pipe length for the different blade angles and $\mathrm{Re}=5000$. 
The convection heat transfer coefficient for the case of $R e$ of 20000 is presented in Figure 8 . The solution presented in this case has similar behavior regarding the cyclic behavior and the sudden spike of $h$ in comparison to the case of $R e=5000$. In this case, $h$ is noticeably higher for $\theta=15^{\circ}$ after $L=0.2 \mathrm{~m}$ in comparison to the other configurations.

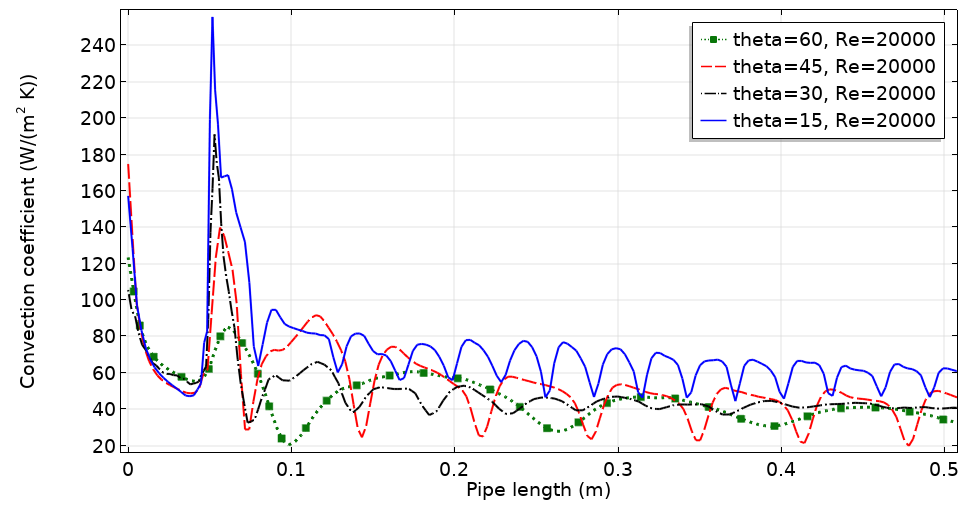

Figure 8: Convection heat transfer coefficient along the pipe length for the different blade angles and $\mathrm{Re}=20000$.

As mentioned earlier, two factors are contributing to the total irreversibility exhibited by the fluid flow. The first one is the heat transfer process, and the second one is the viscous dissipation in the flow region. To assist the contribution of each source of irreversibility, Figure 9 and Figure 10 show, the Bejan number $(B e)$ given by equation (17), evaluated at $R e 5000$ and 20000 . Figure 9 shows $B e$ of the different blade angles at $R e$ of 5000. At the entrance of the pipe channel, $B e$ is extremely small, which indicates that the viscous dissipation is the primary cause of irreversibility. Shortly after the inserted vortex generator, $B e$ starts to increase significantly to the value of unity, which indicates that all the irreversibility is caused by the heat transfer process

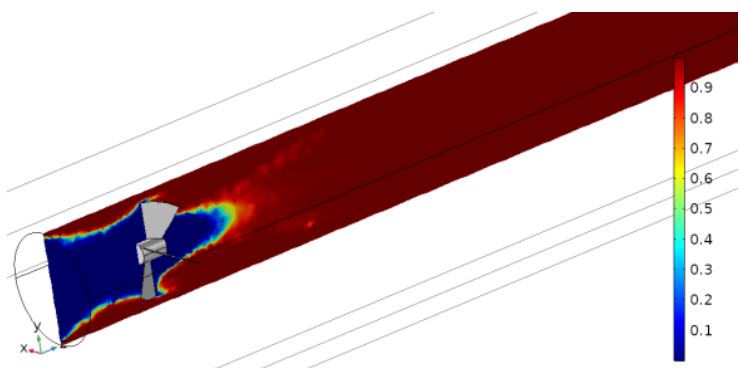

(a)

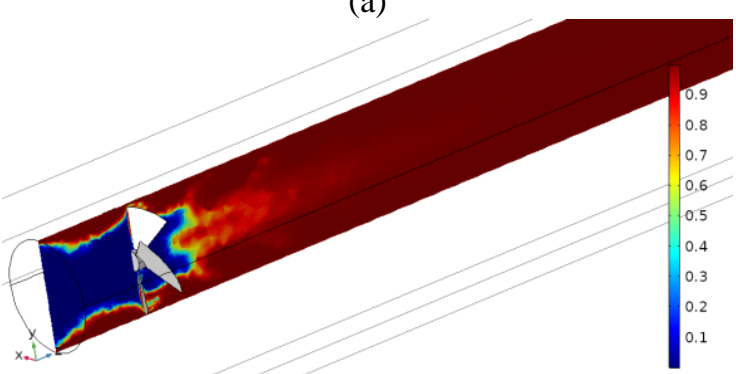

(c)

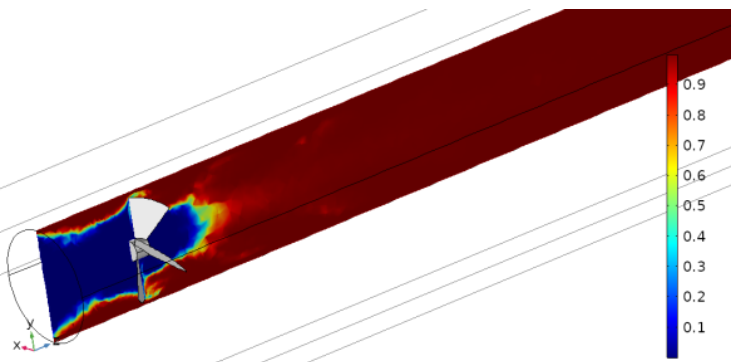

(b)

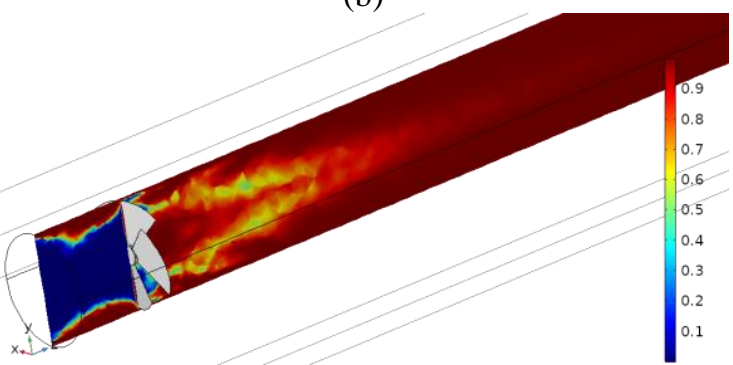

(d)

Figure 9: Bejan number for a flow with $\operatorname{Re}=5000$, (a) $\theta=60^{\circ}$, (b) $\theta=45^{\circ}$, (c) $\theta=30^{\circ}$, (d) $\theta=15^{\circ}$.

Figure 10 shows $B e$ of the different blade angles at $R e$ of 20000 . It is noticed that increasing $R e$ decreases $B e$, which means that viscous dissipation plays a more significant role in the irreversibility process. This figure shows that decreasing $\theta$ affects $B e$ negatively, i.e., the viscous dissipation is the main contributor to the irreversibility. On any rate, $B e$ starts to become 1 after $0.3 \mathrm{~m}$ of the pipe entrance. Although, $B e$ provided a clear picture of the contribution of each factor, yet the total value of $S_{g e n}$ is needed to better evaluate the behavior of the system. 


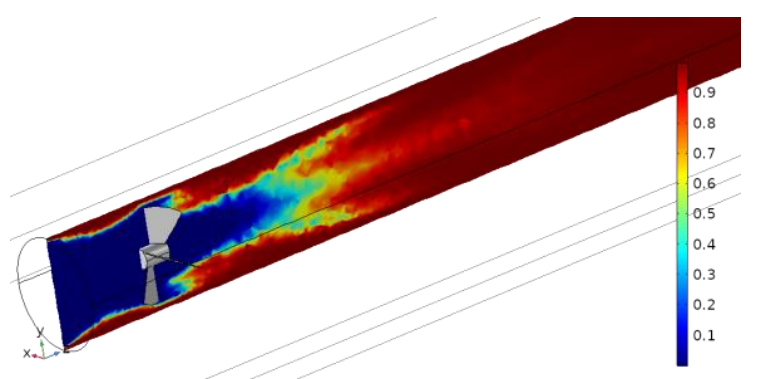

(a)

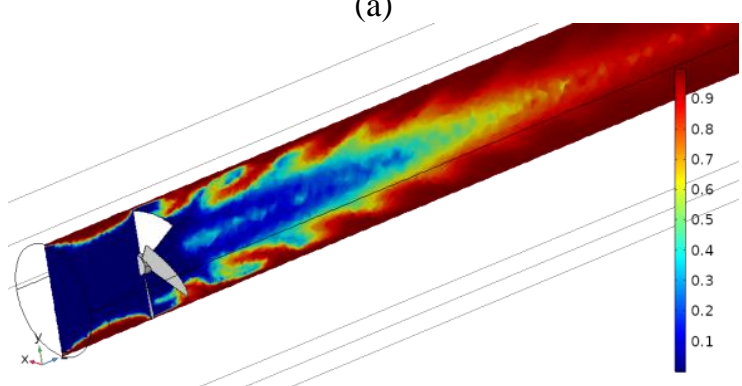

(c)

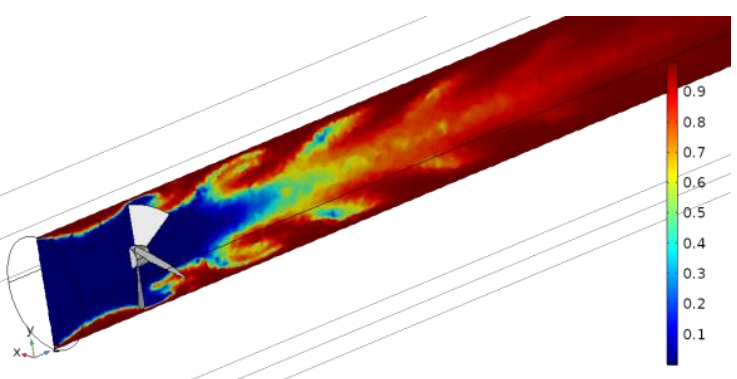

(b)

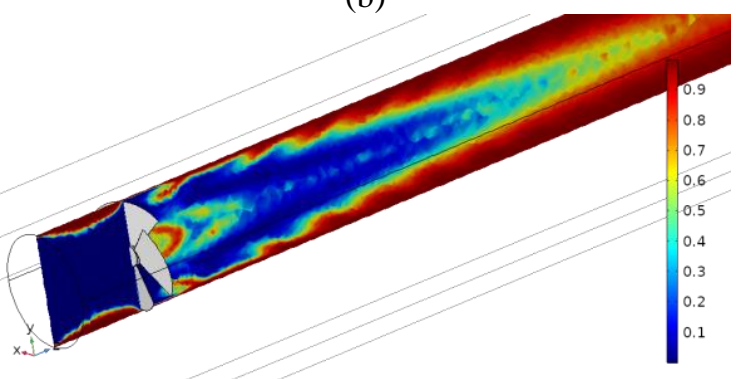

(d)

Figure 10: Bejan number for a flow with $\operatorname{Re}=20000$, (a) $\theta=60^{\circ}$, (b) $\theta=45^{\circ}$, (c) $\theta=30^{\circ}$, (d) $\theta=15^{\circ}$.

The total entropy generation $\left(\dot{S}_{g e n}\right)$ is shown in Figure 11 for all the blade angles. Interestingly, decreasing $\theta$ decreased $\dot{S}_{g e n}$. This could be explained in light of the temperature distribution shown in

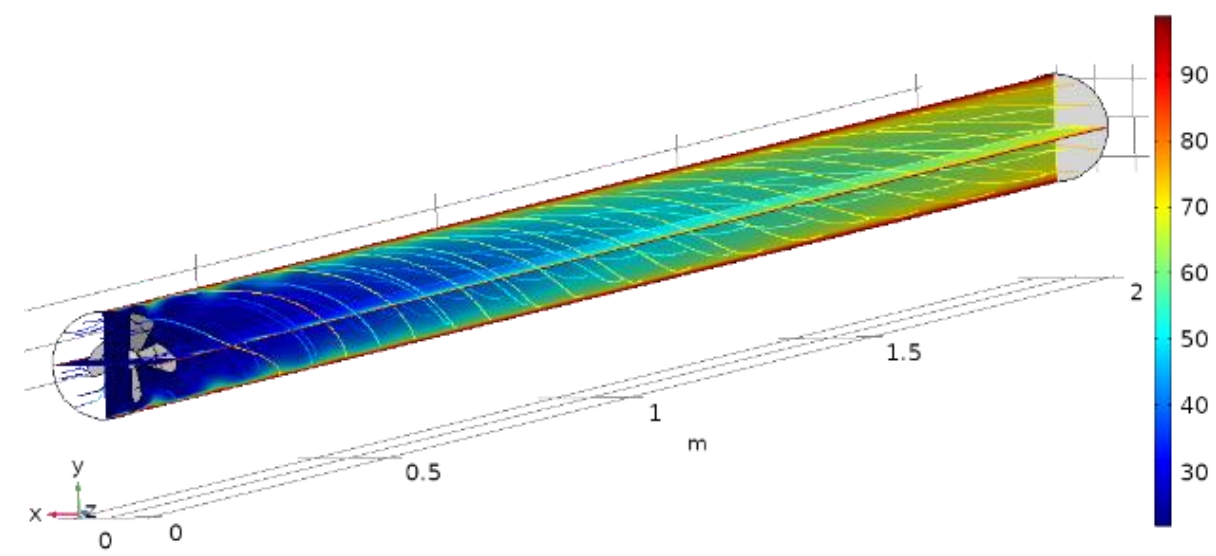

(a)

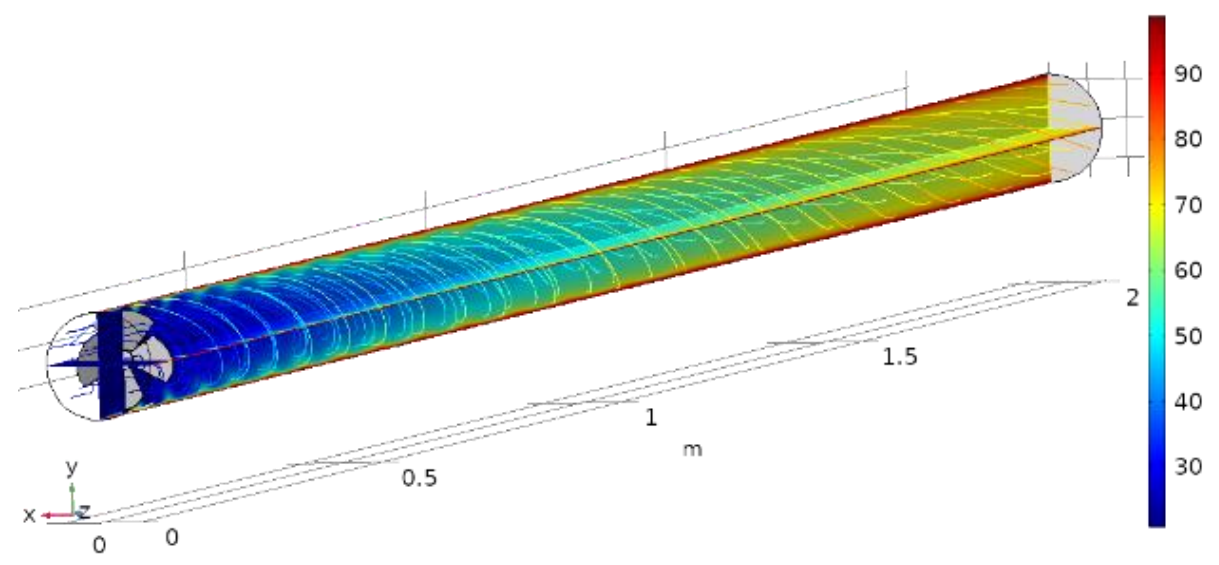

(b) 


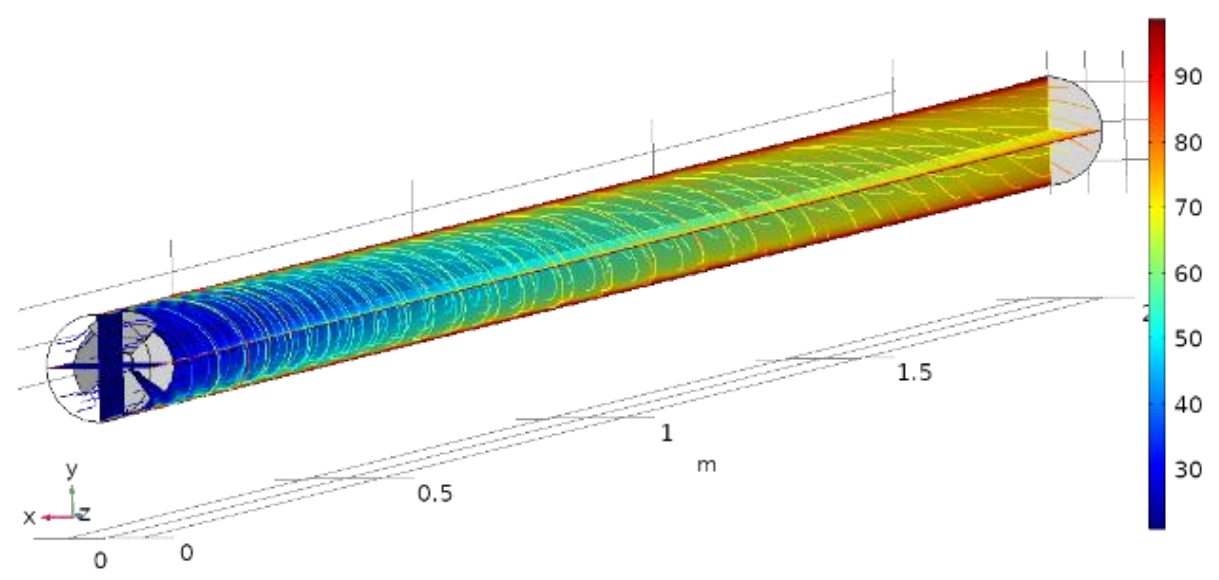

(c)

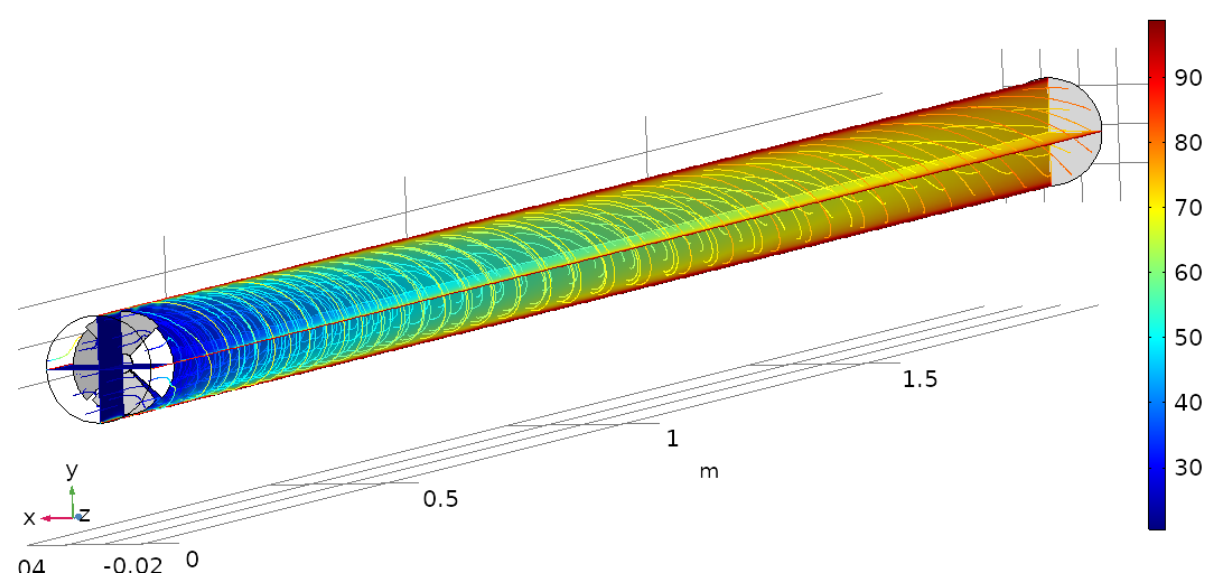

(d)

Figure 5 and

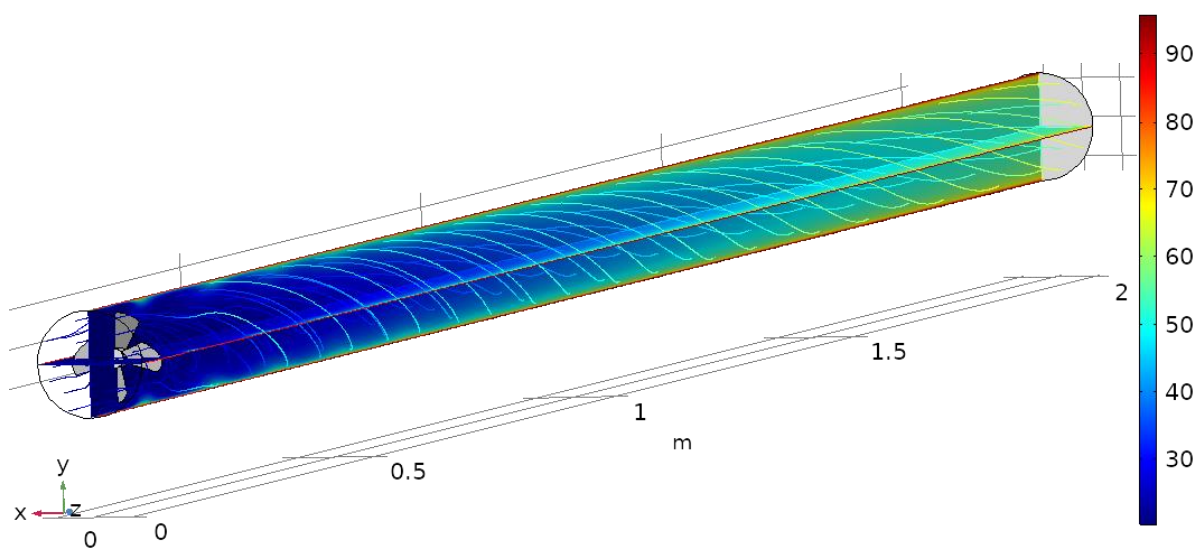

(a) 


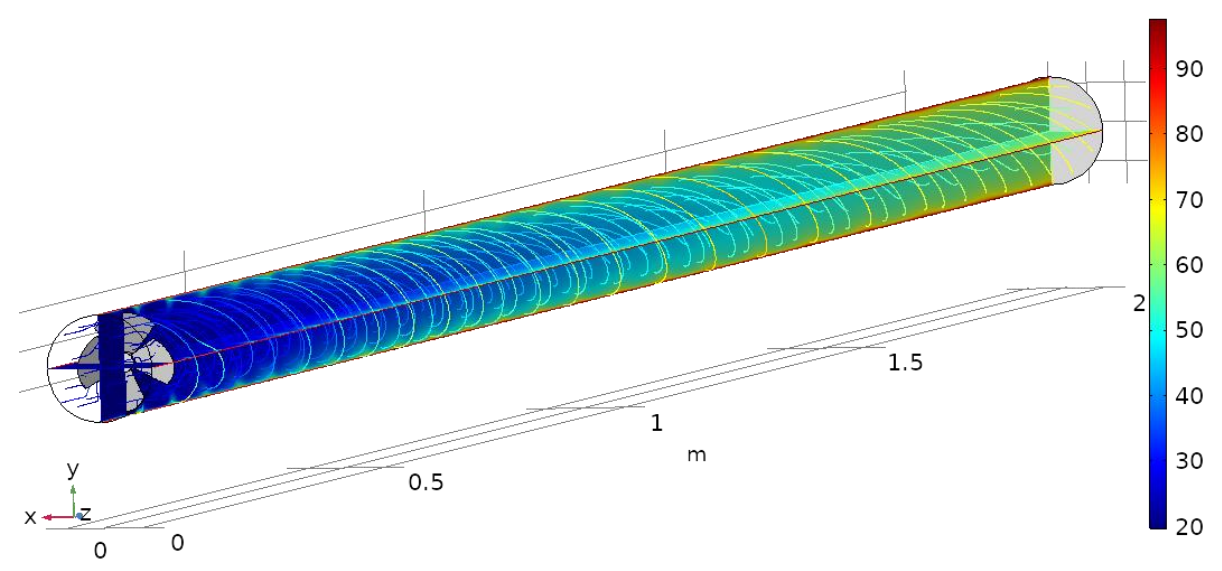

(b)

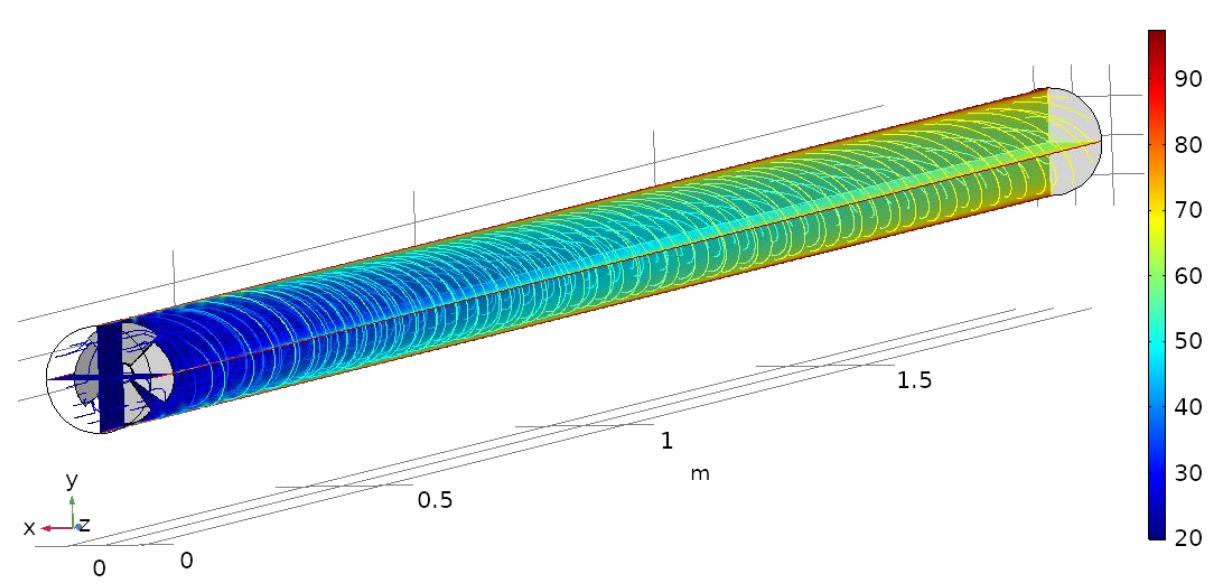

(c)

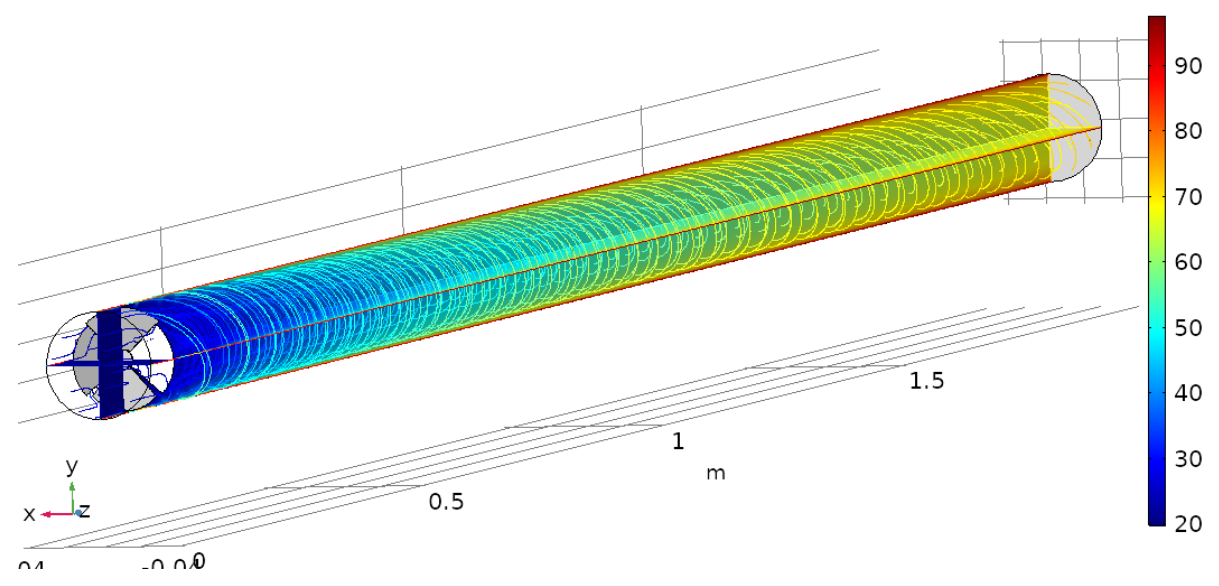

(d)

Figure 6 where the gradient of the temperature profile is smoother for the case of $\theta=15^{\circ}$, which means smaller $\dot{S}_{\text {gen }}$ due to heat transfer. Also, as noted earlier, decreasing $\theta$ enhanced the heat transfer process which directly leads to a smaller $\dot{S}_{g e n}$. This result is consistent with the work of You et al., [33] were increasing the size of the obstacle in the flow region, i.e., decreasing $\theta$ in the current work, lead to lower $\dot{S}_{g e n}$. Although, decreasing $\theta$ caused smaller $\dot{S}_{g e n}$, yet this happened at the expense of higher pumping power. The following analysis will assist the best configuration for the blade angle. 


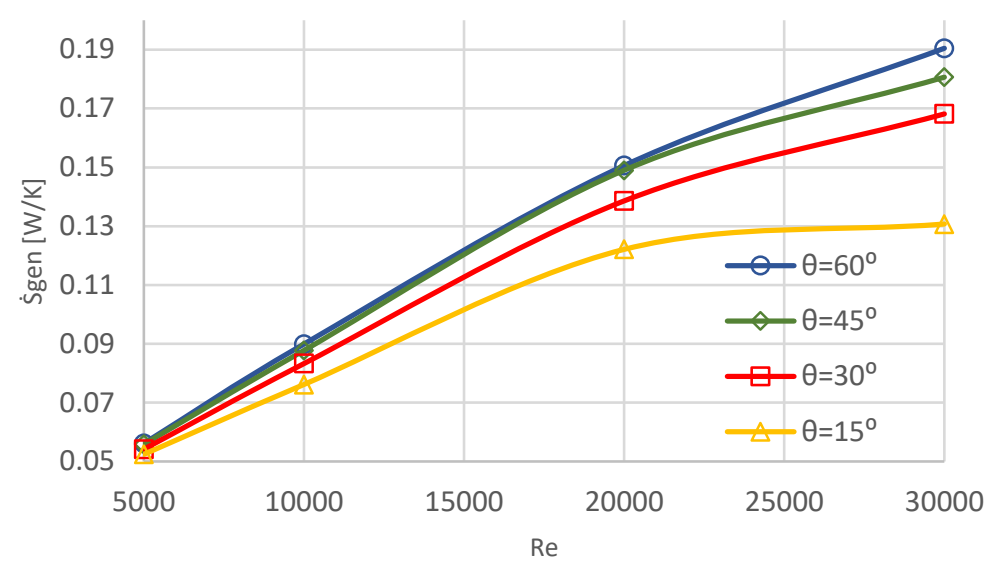

Figure 11: The total entropy generation vs. Re for the different blade angles

Figure 12 shows the variation in Nusselt number ratio versus the Reynolds number for the different blade angles $15^{\circ}, 30^{\circ}, 45^{\circ}$, and $60^{\circ}$. As can be seen from the figure, the ratio of $N u$ rises with increasing $R e$. Another observation that is made from this figure is that decreasing $\theta$ increases $N u$ ratio, which means enhancing the heat transfer process. On average, decreasing the blade angle by $15^{\circ}$ will enhance the $\mathrm{Nu}$ ratio by $8 \%$.

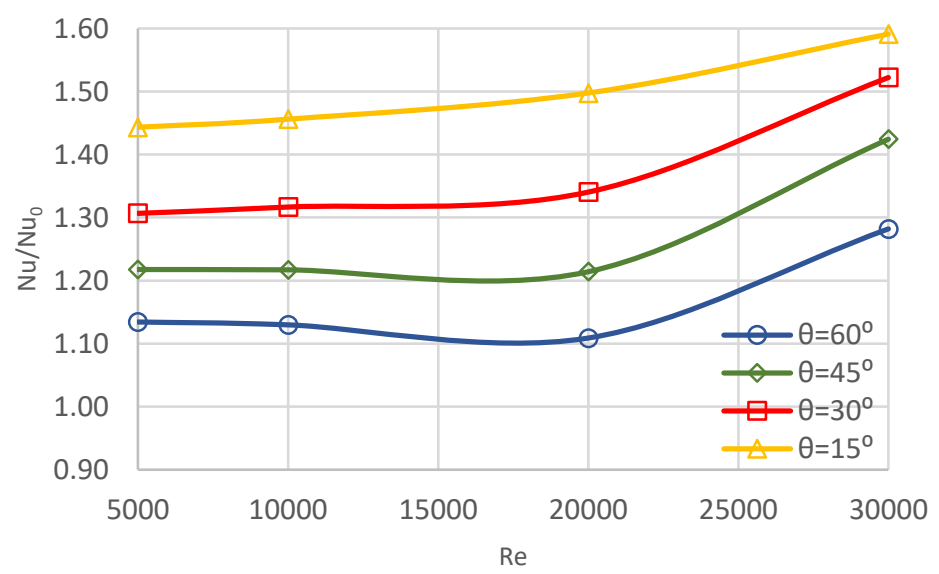

Figure 12: Nusselt number ratio vs. Re for the different blade angles.

Figure 13 demonstrates the variations of the ratio of friction factor with and without the insert against the Reynolds number for different blade angles. The result indicates that the ratio of the friction factor increased as the blade angle decreased. For the case of $\theta=15^{\circ}$ and $R e=30000$, the friction factor increased to 21 folds. Therefore, although the configuration where $\theta=15^{\circ}$ gave the best heat transfer rate, yet it caused the highest pressure drop. Therefore, a thermo-hydraulic criterion should be used in order to better select the most efficient blade angle. 


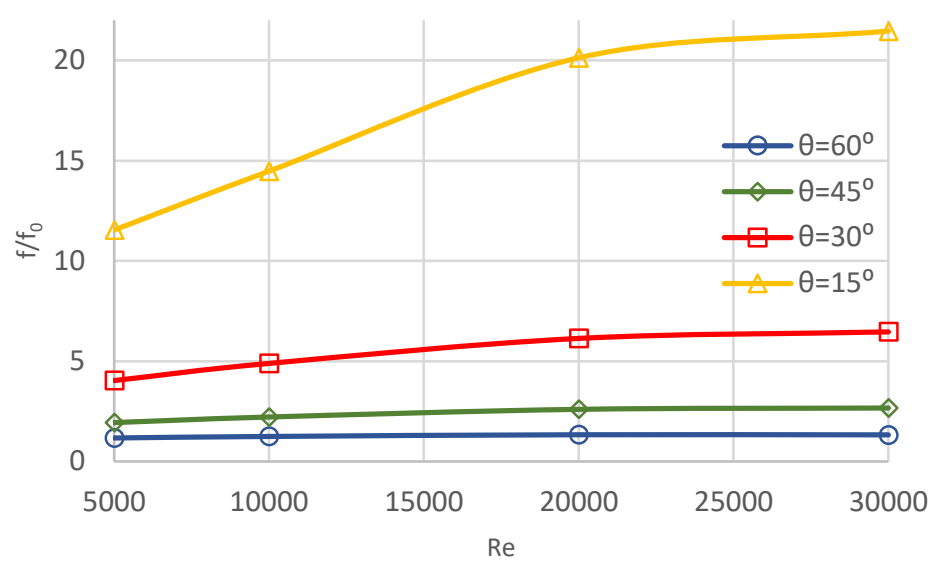

Figure 13: Friction factor number ratio vs. Re for the different blade angles.

The criterion that takes both the heat transfer as well as the pressure drop into consideration is the performance evaluation criteria (PEC), which is given by equation (18). Figure 14 shows the $P E C$ of different configurations vs the considered $R e$. The $P E C$ ranged from 0.55 to 1.167 , over the considered range of $R e$. Although smaller $\theta$ gave a better thermal performance, yet when the hydraulic characteristics are considered, lowering $\theta$ is not desirable. The highest performance is achieved for a blade angle of $60^{\circ}$. For this blade angle, the highest $P E C$ was 1.167 at $R e=30000$.

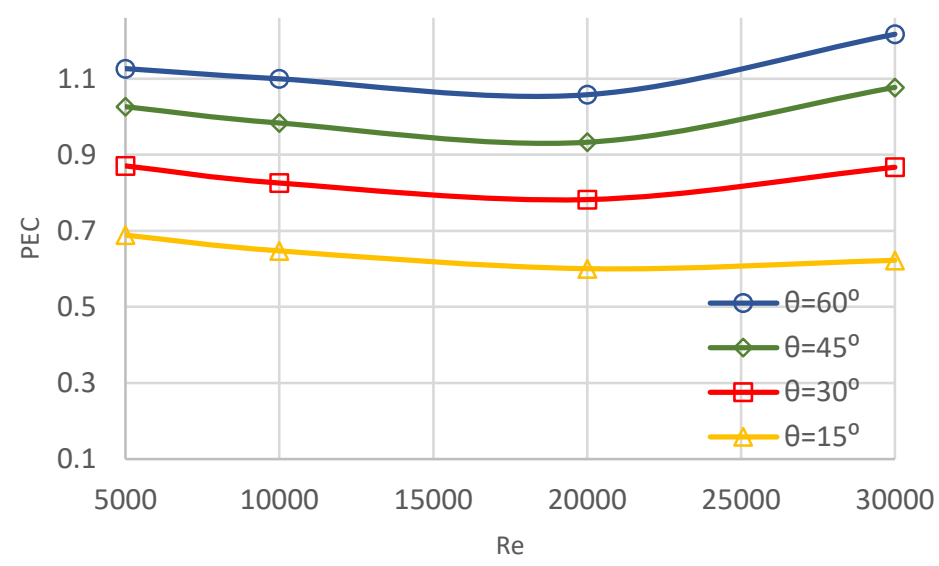

Figure 14: The performance evaluation criteria vs. Re for the different blade angles.

As for the performance of the configuration under consideration, it appears that this type of vortex generator is inferior in terms of performance to other configurations suggested in the literature, such as staggered-winglet perforated-tapes [34]. The $P E C$ of these perforated tapes ranged from 1.25-1.71 for $4180 \leq R e \leq 26,000$. Another type of vortex generator is the V-finned twisted tapes [35], which are reported to provide a better performance 1.21-1.75 over the range of $4000 \leq R e \leq 30000$. Although the twisted tapes provided higher combined thermal and hydrodynamic performance, yet this comes with a more complex manufacturing cost and process. Therefore, although the suggested model is inferior in terms of performance, yet it simpler to manufacture and install.

\section{CONCLUSIONS}

The propeller-type vortex generator was numerically investigated, at different blade angles and Reynolds numbers. The numerical results obtained were in close agreement with the experimental data, over the range of the investigated Reynolds number.

The used vortex generator proved to enhance the heat transfer process noticeably. This enhancement was inversely proportional to the blade angle, where lowering the blade angle $\theta$, positively enhances the heat transfer rate on the expense of higher pressure drop. It is found that decreasing $\theta$ by $15^{\circ}$, caused an increase in the outlet temperature by $4 \%$, on average. The vortex generator also showed a cyclic pattern for the local convection heat transfer coefficient along the tube axis, where it increased by decreasing $\theta$. 
The total entropy generation was investigated as well as the Bejan number. Decreasing $\theta$ resulted in decreasing the total entropy generation $\dot{S}_{g e n}$. The reason for this phenomenon, was due to the enhancement of the heat transfer process where the gradient of the temperature profile was smoother by decreasing $\theta$. Also, it is observed that decreasing $\theta$ caused a higher viscous dissipation resulting in a lower $B e$ at the pipe entrance.

Three different criteria were examined in this study; these were the ratio of Nusselt number, friction factor, and the performance evaluation criteria. The results showed that a decrease in $\theta$ results in an increase Nin $u$ as well as the $f$. Therefore, the combined effect, i.e., heat transfer and fluid flow, was shown using $P E C$ where $\theta=60^{\circ}$ gave the best configuration for this type of applications.

\section{ACKNOWLEDGMENT}

The author would like to express his gratitude to Dr. Teoman Ayhan and Dr. Betul Sarac for their fruitful discussions and insights.

\section{REFERENCES}

[1] Jensen MK, Bergles AE, Shome B. The Literature on Enhancement of Convective Heat and Mass Transfer. J Enhanc Heat Transf 1997;4:1-6. doi:10.1615/JEnhHeatTransf.v4.i1.10.

[2] Patil N, Tandale M. A REVIEW ON SOME PASSIVE TECHNIQUES OF HEAT TRANSFER ENHANCEMENT USING INSERTS. n.d

[3] Eiamsa-ard S, Thianpong C, Eiamsa-ard P. Turbulent heat transfer enhancement by counter/co-swirling flow in a tube fitted with twin twisted tapes. Exp Therm Fluid Sci 2010;34:53-62. doi:10.1016/J.EXPTHERMFLUSCI.2009.09.002.

[4] Seemawute P, Eiamsa-ard S. Thermohydraulics of turbulent flow through a round tube by a peripherally-cut twisted tape with an alternate axis. Int Commun Heat Mass Transf 2010;37:652-9. doi:10.1016/J.ICHEATMASSTRANSFER.2010.03.005.

[5] Murugesan P, Mayilsamy K, Suresh S, Srinivasan PSS. Heat transfer and pressure drop characteristics in a circular tube fitted with and without V-cut twisted tape insert. Int Commun Heat Mass Transf 2011;38:329-34. doi:10.1016/j.icheatmasstransfer.2010.11.010.

[6] Bhuiya MMK, Azad AK, Chowdhury MSU, Saha M. Heat transfer augmentation in a circular tube with perforated double counter twisted tape inserts. Int Commun Heat Mass Transf 2016;74:18-26. doi:10.1016/j.icheatmasstransfer.2016.03.001.

[7] Ebrahimi A, Roohi E, Kheradmand S. Numerical study of liquid flow and heat transfer in rectangular microchannel with longitudinal vortex generators Appl Therm Eng 2015;78:576-83. doi:10.1016/j.applthermaleng.2014.12.006.

[8] Ebrahimi A, Rikhtegar F, Sabaghan A, Roohi E. Heat transfer and entropy generation in a microchannel with longitudinal vortex generators using nanofluids. Energy 2016;101:190-201. doi:10.1016/J.ENERGY.2016.01.102.

[9] Zhu XW, Fu YH, Zhao JQ. A novel wavy-tape insert configuration for pipe heat transfer augmentation. Energy Convers Manag 2016;127:140-8. doi:10.1016/j.enconman.2016.09.006.

[10] Deshmukh PW, Vedula RP. Heat transfer and friction factor characteristics of turbulent flow through a circular tube fitted with vortex generator inserts. Int J Heat Mass Transf 2014;79:551-60. doi:10.1016/J.IJHEATMASSTRANSFER.2014.08.042.

[11] Oni TO, Paul MC. Numerical investigation of heat transfer and fluid flow of water through a circular tube induced with divers' tape inserts. Appl Therm Eng 2016;98:157-68. doi:10.1016/J.APPLTHERMALENG.2015.12.039.

[12] Skullong S, Promvonge P, Thianpong C, Jayranaiwachira N, Pimsarn M. Thermal performance of heat exchanger tube inserted with curved-winglet tapes. Appl Therm Eng 2018;129:1197-211. doi:10.1016/j.applthermaleng.2017.10.110.

[13] Suri ARS, Kumar A, Maithani R. Experimental investigation of heat transfer and fluid flow behaviour in multiple square perforated twisted tape with square wing inserts heat exchanger tube. Heat Mass Transf 2018;54:1813-26. doi:10.1007/s00231-018-2290-x.

[14] Eiamsa-ard S, Promvonge P. Heat transfer characteristics in a tube fitted with helical screw-tape with/without core-rod inserts. Int Commun Heat Mass Transf 2007;34:176-85. doi:10.1016/J.ICHEATMASSTRANSFER.2006.10.006.

[15] Huang S, Wan Z, Wang Q, Tang Y, Yang X. Thermo-hydraulic characteristics of laminar flow in a circular tube with porous metal cylinder inserts. Appl Therm Eng 2017;120:49-63. doi:10.1016/j.applthermaleng.2017.03.117.

[16] Zheng N, Liu P, Shan F, Liu J, Liu Z, Liu W. Numerical studies on thermo-hydraulic characteristics of laminar flow in a heat exchanger tube fitted with vortex rods. Int J Therm Sci 2016;100:448-56. doi:10.1016/j.ijthermalsci.2015.09.008.

[17] Tu W, Xu Z, Zhu Y, Wang Y, Tang Y. Boundary layer redevelops with mesh cylinder inserts for heat transfer enhancement. Int J Heat Mass Transf 2017;109:147-56. doi:10.1016/j.ijheatmasstransfer.2017.02.002.

[18] Liu P, Zheng N, Shan F, Liu Z, Liu W. An experimental and numerical study on the laminar heat transfer and flow characteristics of a circular tube fitted with multiple conical strips inserts. Int J Heat Mass Transf 2018;117:691-709. doi:10.1016/j.ijheatmasstransfer.2017.10.035.

[19] Karagoz S, Afshari F, Yildirim O, Comakli O. Experimental and numerical investigation of the cylindrical blade tube inserts effect on the heat transfer enhancement in the horizontal pipe exchangers. Heat Mass Transf Und Stoffuebertragung 2017;53:2769-84. doi:10.1007/s00231-017-2021-8.

[20] Liu P, Zheng N, Liu Z, Liu W. Thermal-hydraulic performance and entropy generation analysis of a parabolic trough receiver with conical strip inserts. Energy Convers Manag 2019;179:30-45. doi:10.1016/j.enconman.2018.10.057.

[21] Liu Z, Li J, Feng Z, Simon T. Numerical study on the effect of jet spacing on the Swirl flow and heat transfer in the turbine airfoil leading edge region. Numer Heat Transf Part A Appl 2016;70:980-94. doi:10.1080/10407782.2016.1230381.

[22] Faeth GM. Swirl flows. Combust Flame 1986;63:311. doi:10.1016/0010-2180(86)90133-1.

[23] Bali T, Sarac BA. Experimental investigation of decaying swirl flow through a circular pipe for binary combination of vortex generators. Int Commun Heat Mass Transf 2014;53:174-9. doi:10.1016/j.icheatmasstransfer.2014.02.030.

[24] Bali T, Sarac BA. Exergy analysis of heat transfer in a turbulent pipe flow by a decaying swirl generator. Int J Exergy 2008;5:64 doi:10.1504/IJEX.2008.016013.

[25] Eldrainy YA, Saqr KM, Aly HS, Jaafar MNM. CFD insight of the flow dynamics in a novel swirler for gas turbine combustors. Int Commun Heat Mass Transf 2009;36:936-41. doi:10.1016/J.ICHEATMASSTRANSFER.2009.06.013.

[26] Saqr KM, Wahid MA. Effects of swirl intensity on heat transfer and entropy generation in turbulent decaying swirl flow. Appl Therm Eng 2014;70:48693. doi:10.1016/J.APPLTHERMALENG.2014.05.059.

[27] Liu W, Liu P, Wang JB, Zheng NB, Liu ZC. Exergy destruction minimization: A principle to convective heat transfer enhancement. Int J Heat Mass Transf 2018;122:11-21. doi:10.1016/j.ijheatmasstransfer.2018.01.048.

[28] Saraç BA, Bali T. An experimental study on heat transfer and pressure drop characteristics of decaying swirl flow through a circular pipe with a vortex generator. Exp Therm Fluid Sci 2007;32:158-65. doi:10.1016/j.expthermflusci.2007.03.002.

[29] SARAÇ BA. Investigation of heat transfer, pressure drop and performance in decaying swirl flow for different types and statements of axial swirl promoters. Karadeniz Technical University Institute of Science, 2004.

[30] COMSOL Multiphysics® v. 5.4. www.comsol.com. COMSOL AB, Stockholm, Sweden. 
[31] Webb RL. Performance evaluation criteria for use of enhanced heat transfer surfaces in heat exchanger design. Int J Heat Mass Transf 1981;24:715-26. doi:10.1016/0017-9310(81)90015-6.

[32] Winterton RHS. Where did the Dittus and Boelter equation come from? Int J Heat Mass Transf 1998;41:809-10. doi:10.1016/S0017-9310(97)00177-4.

[33] You Y, Fan A, Liang Y, Jin S, Liu W, Dai F. Entropy generation analysis for laminar thermal augmentation with conical strip inserts in horizontal circular tubes. Int J Therm Sci 2015;88:201-14. doi:10.1016/j.ijthermalsci.2014.10.003.

[34] Skullong S, Promvonge P, Thianpong C, Pimsarn M. Heat transfer and turbulent flow friction in a round tube with staggered-winglet perforated-tapes. Int J Heat Mass Transf 2016;95:230-42. doi:10.1016/j.ijheatmasstransfer.2015.12.007.

[35] [35] Promvonge P. Thermal performance in square-duct heat exchanger with quadruple V-finned twisted tapes. Appl Therm Eng 2015;91:298307. doi:10.1016/j.applthermaleng.2015.08.047. 